\title{
Florian Weißofner
}

\section{Essays on Momentum Strategies and Investor Sentiment}

A dissertation submitted to the Faculty of Business, Economics, and Management Information Systems in partial fulfillment of the requirements for the degree of

Doktor der Wirtschaftswissenschaft (Dr. rer. pol.)

Advisors:

Prof. Dr. Klaus Röder

Prof. Dr. Gregor Dorfleitner

\section{Center of Finance}

Faculty of Business, Economics, and Management Information Systems

Universität Regensburg 


\section{Content}

1 Introduction 1

2 Separating Momentum from Reversal in International Stock Markets 9

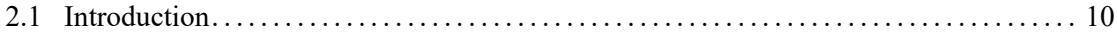

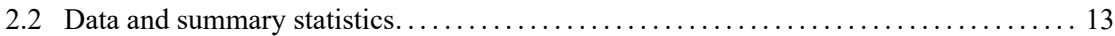

2.3 Abnormal returns of MAX and MIN strategies....................... 16

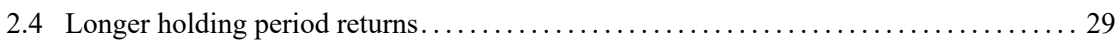

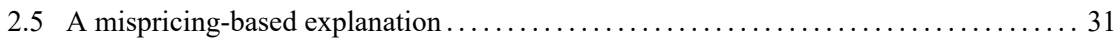

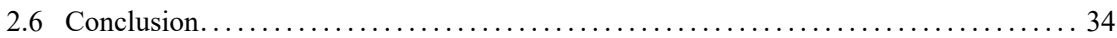

3 Continuing Overreaction: European Evidence $\quad 36$

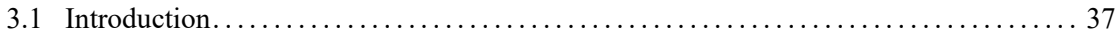

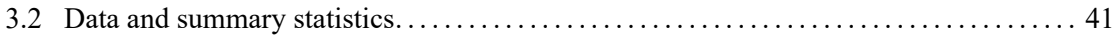

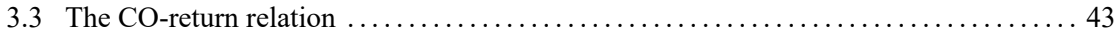

3.4 Return Effects of High and Low CO Measures with Controls ................ 48

3.5 $\mathrm{CO}$ measures within different business conditions ..................... 51

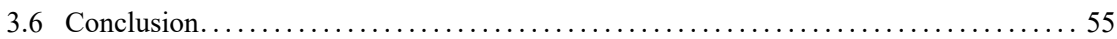

4 Overnight Returns: An International Sentiment Measure $\quad 57$

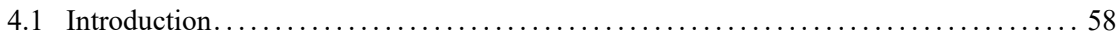

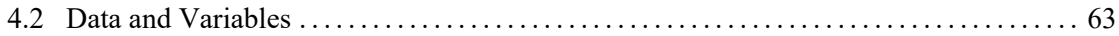

4.3 Short-Term Persistence in Overnight Returns ........................ 67

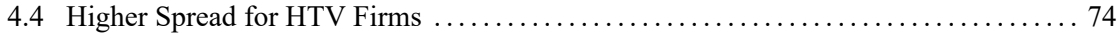

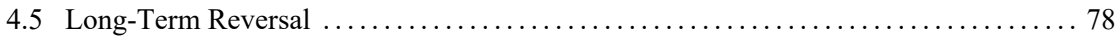

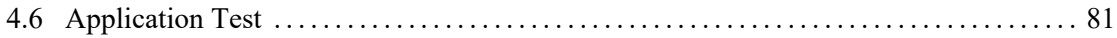

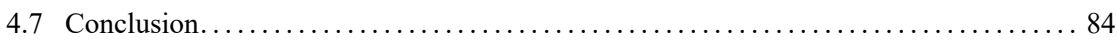

5 Conclusion $\quad 86$

$\begin{array}{llr}6 & \text { Bibliography } & 89\end{array}$ 


\section{List of Tables}

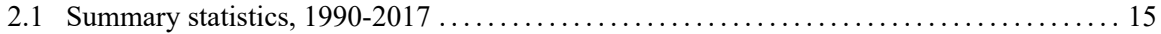

2.2 Benchmark-adjusted returns of standard, MAX, and MIN momentum strategies....... 18

2.3 Robustness of MAX and MIN momentum strategies..................... 22

2.4 Longer holding period returns of MAX and MIN momentum strategies ............. 30

2.5 Returns to MAX and MIN momentum strategies conditional on mispricing .......... 33

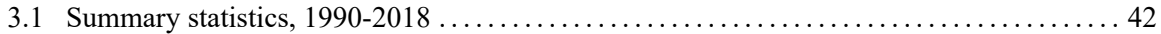

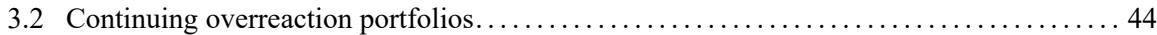

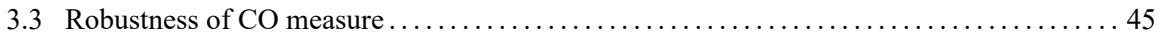

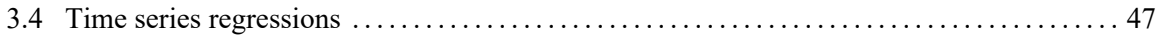

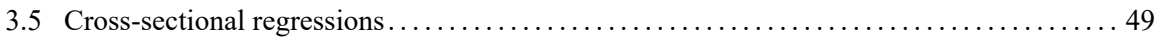

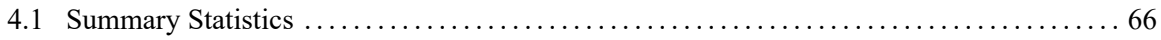

4.2 Persistence of Weekly Overnight Returns and Related Weekly Close-to-Close Returns ... 68

4.3 Cross-Sectional Regressions of Weekly Overnight Returns on Overnight Return

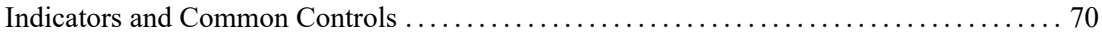

4.4 Cross-Sectional Regressions of Weekly Overnight Returns and Hard-to-Value Proxies . . 74

4.5 Cross-Sectional Regressions for Longer Holding Period Close-to-Close Returns ... . . . . 79

4.6 Cross-Sectional Regressions of Momentum Conditional on Sentiment ............. 82 


\section{List of Figures}

2.1 Momentum premiums conditional upon business conditions $\ldots \ldots \ldots \ldots \ldots \ldots \ldots \ldots 28$

3.1 Premiums conditional upon business conditions ........................ 54 


\section{Chapter 1}

\section{Introduction}

For several decades the capital asset pricing model (CAPM) of Sharpe (1964) and Lintner (1965) has been a fundamental component of finance. The standard CAPM contains only two types of risk, the systematic and the unsystematic. The unsystematic risk includes the individual stock specific risk that is not correlated with the market and can be eliminated by diversification. However, the systematic risk covers the market risks (e.g., recessions or interest rates) and is the only return component in the CAPM that cannot be diversified away. Nevertheless, Basu (1977), Jegadeesh (1990), and Fama and French (1992) provide empirical evidence that cross-sectional return differences even occur by market capitalization, bookto-market, and past stock returns better known as size effect, value effect, and momentum. The momentum anomaly and the consequential suffering from reversal is still one of the most examined anomalies in finance literature. Therefore, this dissertation analyzes novel momentum approaches in international settings which represent alternatives to the traditional momentum approach by Jegadeesh and Titman (1993).

Beside these very well-known anomalies, a large number of return predictive variables has been examined in finance literature. For example, McLean and Pontiff (2016) investigate 97 anomalies based on research history of cross-sectional relations between variables and stock returns. In general, there are two famous distinct explanations. On the one hand, Daniel et al. (1998) were among the first to present a behavioral model based on investors' overconfidence and on the other hand, Conrad and Kaul (1998) suggest a risk-based explanation. A substantial role within the behavioral models is played by the measure of investor sentiment. Baker and Wurgler (2006) developed a sentiment measure for the U.S. equity market and present evidence that market-wide sentiment has effects on the cross-section of the expected returns. It is quite likely that the sentiment measure of Baker and Wurgler is still the most applied sentiment measure in finance literature. However, there are a few restrictions and 
shortcomings of the measure, especially within an international test setting. Recent literature implemented a novel approach by measuring investor sentiment directly at the firm level. Aboody et al. (2018) demonstrate the suitability of overnight returns as a firm-specific measure for investor sentiment. This dissertation empirically analyzes the novel approach by Aboody et al. (2018) in a broad set of international equity markets.

\section{Momentum in the literature}

DeBondt and Thaler $(1985,1987)$ were among the first to show that past losers outperform past winners in the long run. Specifically, they showed that stocks with low returns in the past three to five years have higher subsequent returns than vice versa. This effect later became known as the reversal effect in the long run.

The standard momentum approach that is still current today dates back to Jegadeesh and Titman (1993). They show that over a period of three to twelve months, past winners (based on the prior twelve-month stock return) outperform past losers, and therefore exhibit momentum in the intermediate term. Afterwards, Rouwenhorst (1998) examined momentum in a broad set of international equity markets. Besides the proof that momentum is also present in twelve sample countries, he points out that international momentum is likewise correlated to momentum in the United States. Later studies by Moskowitz and Grinblatt (1999) document momentum even within industries; furthermore Asness et al. (2013) deliver empirical evidence for momentum across different asset classes.

However, all momentum anomalies suffer from a return reversal, and specifically the momentum premium earned in the first year becomes negative in the subsequent years (Jegadeesh and Titman, 2001). Blackburn and Cakici (2017) provide further evidence for the return reversal pattern in a broad international sample of 23 developed countries. Recently, Conrad and Yavuz (2017) invented a method that separated momentum stocks from stocks that gain reversal. They argue that when risk-based characteristics such as size and book-tomarket are taken into account by calculating winner and loser portfolios, a separation is 


\section{Chapter 1 Introduction}

possible. Therefore, they construct a MAX momentum strategy that buys small value winners and sells large growth losers. Likewise, they build a MIN momentum strategy that buys large growth winners and sells small value losers. With their novel approach, they are not only able to gain higher momentum profits in the MAX strategy, but also no significant reversal occurs within this strategy. In contrast, the MIN strategy produces no momentum profits but significant negative returns over longer holding periods.

Overall, two famous attempts to explain momentum and reversal exist in literature. Daniel et al. (1998) explain short-term momentum and long-term reversal observed in a standard momentum approach within a behavioral model based on investors' overconfidence. On the downside, Conrad and Kaul (1998) recommend a risk-based explanation for several market anomalies (including momentum). Jegadeesh and Titman (2002) object the view, arguing that if a risk-based explanation is true, momentum should not suffer from return reversals. Jegadeesh and Titman (2011) contradict the risk-based explanations again by explaining that the magnitude and the persistence of the momentum anomaly over decades are too strong to be explained by risk and therefore favoring a behavioral approach. Recently, Conrad and Yavuz (2017) resume this debate again by arguing that stocks with momentum can be separated from stocks that gain reversal when risk-based characteristics are considered in the selection of winner and loser portfolios. In sum, the debate about whether returns are explained by risk factors or interpreted as a measure of mispricing is still ongoing. Thus, providing good reason for examining the question in this dissertation.

Within the overconfidence explanation an extensive body of literature documents theoretical evidence that momentum leads to higher trading volume. Initially, Odean (1998) demonstrated that trading volume increases when investors are overconfident. Furthermore, Statman et al. (2006) provide supporting evidence for higher trading volume in conjunction with biased self-attribution. Recent literature by Byun et al. (2016) resumes these findings and provides a novel measure that offers the possibility to use trading volume as a proxy for overconfidence, and therefore predict future stock returns. As the direction of overreaction is 


\section{Chapter 1 Introduction}

not known, they argue that the trading volume itself does not predict future stock returns directly. Therefore, by multiplying the trading volume with the sign of the average stock return, they create a measure for continuing overreaction that displays a trend of investors' overconfidence.

\section{Investor sentiment and overnight returns in the literature}

In their pioneering work, Baker and Wurgler (BW hereafter) (2006) challenge the view of the classical finance theory of efficient markets. They were among the first who demonstrated significant effects of investor sentiment on the cross-section of stock returns. Specifically, when sentiment is high, stocks that are more attractive for optimistic investors (e.g., stocks that were small, young, more volatile or unprofitable) gain low returns in the subsequent months while during low sentiment periods, this pattern becomes insignificant or even reverses. Besides the well-known BW sentiment measure, a broad set of literature focuses on market-wide measures for investor sentiment (e.g., Brown and Cliff, 2004 or Stambaugh et al., 2012). However, there is less international sentiment literature and no universal measure is available (Baker et al., 2012). Furthermore, the BW measure uses the exclusive datasets for IPOs from Jay Ritter's website, which delivers data primarily for the U.S. market. Thus, proxies have to be used for international calculations.

Aboody et al. (2018) contribute to the U.S. literature by implementing a novel approach for a firm-specific sentiment measure. More precisely, they document the suitability of overnight returns as a measure of sentiment. Their new approach has the advantage that it is possible to measure sentiment directly at the firm level, and not as a market wide measure. Besides that, the calculations do not require special datatypes or databases, as the opening and closing prices are publicly available data.

Literature on overnight returns is quite young and mainly focuses on U.S. studies. Branch and $\mathrm{Ma}$ (2008) find a negative correlation between overnight returns and subsequent intraday returns. Berkman et al. (2012) deliver supporting evidence and show that this relation is due 


\section{Chapter 1 Introduction}

to a high opening price compared to the intraday prices. Furthermore, they show this behavior is stronger among stocks that are more attractive to retail investors and stocks that are harder to value. Analyzing microsecond tick data, Lou et al. (2019) present new evidence about the cross-section of expected returns by paying particular attention to the exact time the returns accrue. Therefore, they evince that momentum profits on U.S. markets occur entirely overnight while the profits of all other trading strategies occur intraday.

In addition, sentiment against the background of different market anomalies is of special interest. Particularly because Stambaugh et al. (2012) demonstrate that a broad set of anomalies is stronger among high levels of sentiment, and weaker within low sentiment levels, while in their test setting the short leg is always more profitable than the long leg.

\section{Contribution of this thesis}

On the whole, there is still an ongoing debate about the explanation for the momentum anomaly and return reversal as well as about sentiment measures as a perennial issue of finance literature. However, previous literature predominantly focuses on the U.S. equity market, while studies on the European stock market as well as international studies are scarce. This dissertation fills this gap and contributes to the literature by examining momentum anomalies and sentiment measures on a European or even an international stock market sample.

This thesis contributes to the literature in manifold ways. First, it sheds light into separating momentum stocks from stocks that suffer from reversal. Second, it examines a measure for overreaction that better predicts momentum stocks than a standard momentum approach. And third, it examines the suitability of overnight returns as a firm specific sentiment measure on the international stock market. This dissertation investigates different subsamples, i.e. time, size and regions. Besides that, different states of the economy, i.e. market volatility, market states, investor sentiment, market liquidity, default spread and a recession indicator are taken into account. 
Previous literature often focuses on portfolio sorts to examine how average returns vary within different levels of the characteristics. This might be a very useful approach, but portfolio sorts have the potential shortcoming that some of the information is lost through aggregation. Therefore, the Fama and MacBeth (1973) methodology, which provides a test setting that easily allows for multiple control variables, is used additionally. Recent literature by Fama and French (2015) argues that the explanatory power of alternative factor models is superior or at least equal to the explanatory power of traditional models (e.g., the three-factor model by Fama and French (1993) or the four-factor model by Carhart (1997)). These models enable gaining valuable new insights into the cross-section of expected stock returns by studying the stocks at the individual firm level.

This thesis comprises three studies. The subsequent section gives a brief overview of the approach and the contribution of every single article to the literature. The remainder of this thesis is organized as follows. Chapter 2, 3 and 4 cover the three studies, and Chapter 5 outlines the main findings of the three studies and summarizes the thesis.

\section{Separating Momentum from Reversal in International Stock Markets}

It is well established that momentum portfolios suffer from a return reversal over longer holding periods. This paper demonstrates that stocks with momentum can be separated from those with reversal when risk-based expected return characteristics like firm size and bookto-market are taken into account in the selection of winners and losers.

Specifically, this study contributes to the literature by investigating the novel strategies in the broad cross-section of international firms drawn from 20 developed non-U.S. equity markets. More precisely, what is examined is whether a strategy that buys small value winners and sells large growth losers, namely the MAX strategy, yields significantly larger benchmarkadjusted returns over holding periods up to one year, than the MIN strategy, that buys large growth winners and sells small value losers. To ex ante separate momentum stocks from stocks that display return reversal, the return behavior of the MAX and MIN strategies over 


\section{Chapter 1 Introduction}

longer holding periods up to three years is further investigated. Given that the well-known firm characteristics used in this study can be interpreted as measures of mispricing (e.g., Lakonishok et al, 1994; Shleifer and Vishney, 1997; Hirshleifer and Jiang, 2010), that may add to our understanding of the varying return behavior of the MAX and MIN strategies. Therefore, it is examined whether the performance of the two distinct strategies are the outcome of cross-sectional mispricing.

\section{Continuing Overreaction: European Evidence}

Building upon the insights that continuing overreaction causes momentum in the short run, Byun et al. (2016) construct a completely novel measure of continuing overreaction. Motivated by their findings for the stock market in the United States, this study extends these findings for the European stock market.

In detail, this study contributes to the literature by examining the novel continuing overreaction measure introduced by Byun et al. (2016) in the broad cross-section of 15 European equity markets. Besides the past stock return, the measure includes the trading volume of a stock. First, this study tests whether a positive return relation exists between firms with a high measure of continuing overreaction and firms with lower continuing overreaction values. Second, the return behavior within the cross-section and added established return determinants is investigated. And third, it is tested whether the return premium is also present within different business conditions, as it is known that the momentum profits vary within different states of the economy. Therefore, the measure is tested in contracting/pessimistic business conditions and compared to expanding/optimistic business conditions.

\section{Overnight Returns: An International Sentiment Measure}

This study focuses on the suitability of overnight returns as a firm-specific sentiment measure in an international stock market sample. Previous literature by Aboody et al. (2018) finds strong evidence that overnight returns function as a measure of sentiment on the U.S. stock 
market. The substantial contributions for the international equity markets are interesting especially for three reasons. First, there is still no ubiquitous sentiment measure at the firmlevel. Second, until now, international literature has to use U.S. sentiment measures as proxies. And third, the existing measures mostly require special datatypes. The novel approach fills this gap and offers an international applicable measure.

Furthermore, to examine the suitability on the international stock market, the study first investigates whether overnight returns persist over the subsequent weeks. Second, it is examined whether the short-term return persistence is greater among stocks that are objectively harder-to-value. For the validity of the assumption, the overnight return persistence should be stronger among firms that are objectively harder-to-value. In the third step, the return behavior of stocks with high overnight returns in the long run is examined. Temporary mispricing is a characteristic that would be expected of a sentiment measure; consequently, in the long run, returns should be smaller among firms with high overnight returns. Finally, to examine the validity of overnight returns as a firm-specific sentiment measure, they are tested in the context of the momentum anomaly, and even the explanatory power beyond the well-known BW market-wide sentiment measure is investigated. 


\title{
Chapter 2
}

\section{Separating Momentum from Reversal in International Stock}

\section{Markets}

This research project is joint work with Christian Walkshäusl and Ulrich Wessels. The paper has been published as: Christian Walkshäusl, Florian Weißofner and Ulrich Wessels (2019), Separating Momentum from Reversal in International Stock Markets, Journal of Asset Management 20(2): 111-123.

\begin{abstract}
Taking into account expected return characteristics like firm size and book-tomarket in the selection of winners and losers helps to ex ante separate stocks with momentum from those that exhibit reversal in international equity markets. A strategy that buys small value winners and sells large growth losers generates significantly larger momentum profits than a standard momentum strategy, is robust to common return controls, and does not suffer from return reversals for holding periods up to three years. The superior performance of the strategy is attributable to a rather systematic exploitation of cross-sectional mispricing among momentum stocks.
\end{abstract}

Keywords Momentum; Reversal; Return predictability; Mispricing; International markets 


\section{Chapter 2 Separating Momentum from Reversal in International Stock Markets}

\subsection{Introduction}

Over the last three decades, the momentum effect has become one of the most examined return patterns in finance. In their seminal work, Jegadeesh and Titman (1993) demonstrate that a strategy that buys past winners and sells past losers produces large abnormal returns for holding periods up to one year. Since then, the momentum effect has been documented in international equity markets, within industries, and across different asset classes (Rouwenhorst, 1998; Moskowitz and Grinblatt, 1999; Asness et al., 2013). However, over longer holding periods, momentum portfolios, in general, suffer from a return reversal pattern, i.e., the abnormal returns earned over the first year after portfolio formation reverse or even turn negative in subsequent years (Jegadeesh and Titman, 2001; Blackburn and Cakici, 2017).

Despite the enormous body of literature on the momentum effect, explanations for the return behavior of momentum stocks remain an ongoing debate. Daniel et al. (1998) were among the first to present a behavioral model based on investors' overconfidence that explains the short-term return continuation and long-term return reversal patterns of typical momentum strategies. Conrad and Kaul (1998) suggest a risk-based explanation that is, however, contradicted by Jegadeesh and Titman (2002) who argue that momentum portfolios should not suffer from return reversals if the risk-based interpretation is correct. ${ }^{1}$

Recently, Conrad and Yavuz (2017) take up again this debate by arguing that stocks with momentum can be separated from those that exhibit reversal when risk-based expected return characteristics like firm size and book-to-market are taken into account in the selection of winners and losers. Assuming that these firm characteristics are responsible for differences in expected returns (Fama and French, 1992), they construct two distinct momentum strategies that differ in their underlying risk characteristics. The MAX momentum strategy takes a long position in high-risk winners, i.e., small value winners, and a short position in

\footnotetext{
1 See, Jegadeesh and Titman (2011) for an extended review of the literature.
} 


\section{Chapter 2 Separating Momentum from Reversal in International Stock Markets}

low-risk losers, i.e., large growth losers. Analogously, the MIN momentum strategy goes long in low-risk winners (large growth winners) and short in high-risk losers (small value losers).

Studying the U.S. equity market, Conrad and Yavuz (2017) find that the MAX strategy does not only yield larger momentum profits than the standard momentum strategy in the short run, it also does not display significant return reversals for holding periods beyond one year. In contrast to that, the MIN strategy produces no significant momentum profits in the short run but suffers from substantial and significant return reversals in the long run. Thus, shortterm return continuation and long-term return reversals are not necessarily linked. Taking into account expected return characteristics like firm size and book-to-market in the selection of winners and losers helps to ex ante separate stocks with momentum from those that exhibit reversal.

The approach of Conrad and Yavuz (2017) seems to be related to the style momentum of Chen and DeBondt (2004) who propose a strategy that goes long in firms with in-favor styles, e.g., being small value stocks, and short in firms with out-of-favor styles, e.g., being large growth stocks, based on the past price performance of these style characteristics. However, there exist clear differences. First, Chen and DeBondt (2004) document in their study that style momentum is distinct from pure price momentum by showing that both strategies possess unique information about subsequent stock returns that is not captured by the other strategy. Second, though the MAX and MIN strategies also take into account firm size and book-to-market in the selection of winners and losers, the focus of these strategies is on using these characteristics as risk measures for separating high-risk from low-risk momentum stocks. Consequently, the strategies' long and short legs are uniformly defined. In contrast, the long and short leg portfolios of style momentum strategies can potentially also consist of mid-cap blend-style stocks or non-dividend-paying stocks, which are not in the center of attention of the MAX and MIN strategies. Third and finally, while the motivation of Chen and DeBondt (2004) is the improvement of style rotation strategies with respect to firm size 


\section{Chapter 2 Separating Momentum from Reversal in International Stock Markets}

and value/growth, the MAX and MIN strategies are motivated by the idea that momentum can be separated from reversal for constructing enhanced momentum-based investment strategies.

In this paper, we contribute to the literature by studying the findings of Conrad and Yavuz (2017) outside the United States. As with any finding in empirical research, the decomposition of momentum and reversal could be the result of data snooping in the sense of Lo and MacKinlay (1990) and therefore be sample-specific. To address this concern, we independently examine in this study the novel MAX and MIN strategies in the broad crosssection of international firms drawn from 20 developed non-U.S. equity markets. Obtaining results similar to the previous U.S. evidence in Conrad and Yavuz (2017) would strengthen their findings and may lead to a better understanding of the momentum and reversal return patterns across equity markets.

From the previous U.S. evidence, we derive three hypotheses that we test out-of-sample in non-U.S. equity markets. The first hypothesis directly addresses whether international stock returns conform to the same pattern observed in the United States.

H1: A strategy that buys small value winners and sells large growth losers, the MAX strategy, yields significantly larger benchmark-adjusted returns over holding periods up to one year than a strategy that buys large growth winners and sells small value losers, the MIN strategy.

Showing that the short-term performance of the MAX strategy is superior to the MIN strategy is only the first part of the key results of Conrad and Yavuz (2017). Second and even more important may be the finding that considering expected return characteristics like firm size and book-to-market in the selection of winners and losers helps to ex ante separate momentum stocks that display return reversals from those that do not. Therefore, we further investigate the return behavior of the MAX and MIN strategies over longer holding periods up to three years and formulate our second hypothesis as follows. 
H2: Over holding periods beyond one year, the MAX strategy displays no return reversal, while the MIN strategy exhibits significant return reversal.

The distinct return behavior of the MAX and MIN strategies may be attributable to the varying underlying risks associated with different levels of firm size and book-to-market, as argued by Conrad and Yavuz (2017). However, these well-known firm characteristics can also be interpreted as measures of mispricing (e.g., Lakonishok et al., 1994; Shleifer and Vishney, 1997; Hirshleifer and Jiang, 2010). Though Conrad and Yavuz (2017) reject that the level of market-wide mispricing as measured by market states and the investor sentiment is influential in the results observed, they do not rule out explanations based on crosssectional mispricing. That is, the possibility that the different return behavior of the two strategies is the result of a rather systematic exploitation of existing mispricing among momentum stocks that is induced by taking into account mispricing-related measures like firm size and book-to-market in the stock selection procedure. Because mispricing at the individual firm level may add to our understanding of the varying return behavior of the MAX and MIN strategies, we formulate our third and final hypothesis as follows.

H3: The strong performance of the MAX strategy and the weak performance of the MIN strategy are the outcome of cross-sectional mispricing.

The remainder of the paper is organized as follows. The next section describes the data and variables used in this study. The subsequent sections test the outlined hypotheses and present the empirical results. The final section concludes the paper.

\subsection{Data and summary statistics}

The dataset used in this study consists of an international sample of firms from 20 developed non-U.S. equity markets. Our sample selection resembles the countries included in the wellknown EAFE (Europe, Australia, and the Far East) stock market benchmark from MSCI which measures the foreign stock market performance outside of North America. We collect monthly total return data on common stocks from Datastream and firm-level accounting 


\section{Chapter 2 Separating Momentum from Reversal in International Stock Markets}

information from Worldscope. To ensure that accounting information is known before the returns are calculated, we match the latest accounting information for the fiscal year ending in the previous calendar year with stock returns from July of the current year to June of the subsequent year throughout the paper. All data are denominated in U.S. dollars. To ensure that tiny or illiquid stocks do not drive our results, we follow Ang et al. (2009) and exclude very small firms by eliminating the $5 \%$ of firms with the lowest market equity in each country. In addition, as in Fama and French (1992), we also exclude firm-year observations with negative book equity and financial firms with Standard Industrial Classification (SIC) codes between 6000 and 6999. The sample period is from July 1990 to June 2017 (henceforth 1990-2017), and the sample comprises on average 7652 firms per month. Distributional statistics for the sample firms across countries are given in Panel A of Table 2.1.

The variables used in this study are defined as follows. A firm's size (SZ) is its market equity (stock price multiplied by the number of shares outstanding) measured as of June each year in million U.S. dollars. Book-to-market (BM) is the ratio of book equity to market equity at the fiscal year-end. Momentum (MOM) is the cumulative prior six-month stock return, skipping the most recent month (Jegadeesh and Titman, 1993). Following Fama and French (2015), operating profitability (OP) is revenues minus cost of goods sold and interest expense, all divided by book equity. ${ }^{2}$ Investment (INV) is the annual change in total assets divided by lagged total assets. To proxy for systematic mispricing in the later analysis, we employ a financing-based misvaluation measure that is based on Bradshaw et al.'s (2006) external financing (XFIN) variable. XFIN is the sum of net equity financing and net debt financing divided by lagged total assets. Net equity financing is the sale of common and preferred stock minus the purchase of common and preferred stock minus cash dividends

\footnotetext{
2 We do not include selling, general and administrative expenses, as this item is not broadly available among international firms. The return predictability of operating profitability is, however, not affected by this adjustment.
} 


\section{Chapter 2 Separating Momentum from Reversal in International Stock Markets}

paid. Net debt financing is the issuance of long-term debt minus the reduction in long-term debt. $^{3}$

Table 2.1 Summary statistics, 1990-2017

Panel A: Sample countries

\begin{tabular}{lrlr}
\hline Country & Firms & Country & Firms \\
\hline Australia & 745 & Japan & 2631 \\
Austria & 56 & Netherlands & 109 \\
Belgium & 79 & New Zealand & 68 \\
Denmark & 97 & Norway & 114 \\
Finland & 85 & Portugal & 49 \\
France & 530 & Singapore & 311 \\
Germany & 523 & Spain & 98 \\
Hong Kong & 490 & Sweden & 233 \\
Ireland & 39 & Switzerland & 144 \\
Italy & 159 & United Kingdom & 1092 \\
\hline
\end{tabular}

Panel B: Variables

\begin{tabular}{lrrrc}
\hline Variable & Mean & 25 th & Median & 75th \\
\hline SZ & 955 & 40 & 126 & 464 \\
BM & 0.96 & 0.40 & 0.72 & 1.21 \\
MOM & 0.05 & -0.14 & 0.01 & 0.18 \\
OP & 0.74 & 0.25 & 0.52 & 0.92 \\
INV & 0.16 & -0.04 & 0.05 & 0.18 \\
XFIN & 0.08 & -0.04 & -0.01 & 0.04 \\
\hline
\end{tabular}

This table presents summary statistics for the countries included in the international (EAFE) sample and the variables used in this study. Panel A reports the average number of firms per month in each country over the sample period from July 1990 to June 2017. Panel B reports the mean, 25th percentile, median, and 75th percentile of the variables. Firm size (SZ) is market equity (stock price multiplied by the number of shares outstanding) as of June of each year in million U.S. dollars. Bookto-market (BM) is the ratio of book equity to market equity at the fiscal year-end. Momentum (MOM) is the cumulative prior six-month stock return, skipping the most recent month. Operating profitability (OP) is revenues minus cost of goods sold and interest expense, all divided by book equity. Investment (INV) is the annual change in total assets divided by total assets. External financing (XFIN) is the sum of net equity financing and net debt financing divided by lagged total assets. Net equity financing is the sale of common and preferred stock minus the purchase of common and preferred stock minus cash dividends paid. Net debt financing is the issuance of long-term debt minus the reduction in longterm debt.

3 In line with Hirshleifer and Jiang (2010), we do not include the change in current debt, as it does not reflect market timing. 


\section{Chapter 2 Separating Momentum from Reversal in International Stock Markets}

Panel B of Table 2.1 summarizes the distributional statistics of the variables over the 19902017 sample period. A typical firm in our international sample has a size of $\$ 955$ million in terms of market equity, an average relative valuation based on book-to-market of 0.96 , and a mean past six-month return of $5 \%$.

\subsection{Abnormal returns of MAX and MIN strategies}

In this section, we test hypothesis H1 that the MAX strategy yields larger benchmarkadjusted returns than the MIN strategy. To do so, we examine the returns to winners and losers on the MAX and MIN strategies at the individual firm level using the Fama and MacBeth (1973) methodology and conduct differences-of-means tests on the average coefficient estimates from the regressions. For comparison purposes, we also include the standard momentum strategy in the analysis to gauge the strength of the MAX and MIN momentum premiums in relation to the unconditional momentum investing approach in international equity markets.

In particular, we estimate three different specification variants nested within the following firm-level cross-sectional regression, where the future twelve-month holding period return of firm $i$ in month $t$ is regressed on two binary indicator variables, denoted Long and Short, in conjunction with common controls that are all available before the month in which the return measurement begins:

$$
\begin{aligned}
& r_{i, t}=a_{0, t}+a_{1, t} \mathrm{Long}_{i, t}+a_{2, t} \mathrm{Short}_{i, t}+a_{3, t} \ln \left(\mathrm{SZ}_{i, t}\right)+a_{4, t} \mathrm{BM}_{i, t}+a_{5, t} \mathrm{OP}_{i, t}+a_{6, t} \mathrm{INV}_{i, t}+ \\
& \text { Country Dummies } i, t+e_{i, t} \text {. }
\end{aligned}
$$

We apply Newey and West (1987) adjusted $t$-statistics here and in all subsequent regressions to correct for the holding period overlap in the statistical inference (Jegadeesh and Titman, 1993). An indicator variable takes the value of one if the underlying condition holds for a firm and zero otherwise. For the standard momentum strategy, Long and Short are equal to 


\section{Chapter 2 Separating Momentum from Reversal in International Stock Markets}

one if the firm's past six-month return is in the top or bottom tercile of the MOM distribution, respectively. Thus, the long leg describes winners, while the short leg denotes losers. When studying the MAX and MIN strategies, the indicator variables also take into account the firm's size and book-to-market ratio as expected return characteristics in line with Conrad and Yavuz (2017). For the MAX strategy, Long is equal to one if the firm has a past-six month return in the top tercile of the MOM distribution and simultaneously a firm size in the bottom tercile of the SZ distribution and a book-to-market ratio in the top tercile of the BM distribution. Thus, classifying the firm as a small value winner. On the other hand, Short is equal to one if the firm has a past-six month return in the bottom tercile of the MOM distribution and simultaneously a firm size in the top tercile of the SZ distribution and a bookto-market ratio in the bottom tercile of the BM distribution. Thus, classifying the firm as a large growth loser. For the MIN strategy, the indicator variables are defined in an analogous manner using the tercile classifications based on SZ, BM, and MOM. In particular, Long is here equal to one if the firm is a large growth winner and Short is equal to one if the firm is a small value loser. ${ }^{4}$

Taking into account the most recent developments in asset pricing (Fama and French, 2015), the set of common control variables includes firm size, book-to-market, operating profitability, and investment for measuring benchmark-adjusted returns. Except for MOM, which is updated monthly, the other explanatory variables are updated each June. Furthermore, since we combine firms from multiple countries in the analysis, we include country dummies here and in all subsequent regressions to control for possible country effects.

\footnotetext{
${ }^{4}$ For each variable, we use the full SZ, BM, and MOM distribution across all sample firms, so that the stock selection procedure corresponds to independent sorts on the three variables, as in Conrad and Yavuz (2017).
} 
Chapter 2 Separating Momentum from Reversal in International Stock Markets

Table 2.2 Benchmark-adjusted returns of standard, MAX, and MIN momentum strategies

\begin{tabular}{lcccccc}
\hline & \multicolumn{3}{c}{ Regression Estimates } & \multicolumn{3}{c}{ Difference-of-Means Tests } \\
\hline Specification & $(1)$ & $(2)$ & $(3)$ & $(2)-(1)$ & $(3)-(1)$ & $(2)-(3)$ \\
Strategy & Standard & MAX & MIN & & & \\
\hline \multirow{2}{*}{ Long } & 1.74 & 3.63 & 1.65 & 1.89 & -0.09 & 1.98 \\
& $(2.58)$ & $(4.89)$ & $(1.43)$ & $(3.16)$ & $(-0.13)$ & $(2.21)$ \\
Short & -1.83 & -3.70 & 0.45 & -1.87 & 2.28 & -4.15 \\
& $(-1.56)$ & $(-3.20)$ & $(0.52)$ & $(-3.35)$ & $(2.97)$ & $(-4.26)$ \\
SZ & -0.37 & -0.08 & -0.29 & 0.29 & 0.08 & 0.21 \\
& $(-1.86)$ & $(-0.34)$ & $(-1.35)$ & $(4.09)$ & $(2.43)$ & $(2.78)$ \\
BM & 2.96 & 2.78 & 3.26 & -0.18 & 0.31 & -0.48 \\
& $(4.98)$ & $(4.58)$ & $(5.32)$ & $(-2.99)$ & $(2.13)$ & $(-3.36)$ \\
OP & 1.50 & 1.55 & 1.53 & 0.04 & 0.02 & 0.02 \\
& $(8.90)$ & $(8.98)$ & $(8.92)$ & $(1.30)$ & $(0.97)$ & $(1.56)$ \\
INV & -2.82 & -2.82 & -2.94 & -0.01 & -0.12 & 0.11 \\
& $(-4.40)$ & $(-4.29)$ & $(-4.52)$ & $(-0.14)$ & $(-1.71)$ & $(2.73)$ \\
& & & & & & \\
R & 0.14 & 0.14 & 0.14 & & & \\
\multirow{2}{*}{ Long-Short } & 3.57 & 7.34 & 1.20 & 3.76 & -2.38 & 6.14 \\
& $(2.24)$ & $(4.16)$ & $(0.78)$ & $(5.90)$ & $(-3.45)$ & $(6.17)$ \\
\hline
\end{tabular}

This table presents average coefficient estimates and associated Newey-West adjusted $t$-statistics (in parentheses) from monthly firm-level cross-sectional regressions along with difference-of-means tests on the average coefficients between the strategies. The dependent variable is the firm's future twelve-month stock return. Long and Short are binary indicator variables that take the value of one if the underlying condition holds for a firm and zero otherwise. Depending on the considered strategy, the conditions are defined as follows. Standard (Long: winner, Short: loser), MAX (Long: small value winner, Short: large growth loser), MIN (Long: large growth winner, Short: small value loser). The classification of firms is based on terciles using the SZ, BM, and MOM distributions. The additional independent variables are firm size (SZ), book-to-market (BM), operating profitability (OP), and investment (INV) and all regressions include country dummies. $\mathrm{R}^{2}$ is adjusted for degrees of freedom. The last row provides the average return premium associated with the given strategy in percent per year based on the difference between the long and short leg coefficient estimates.

Table 2.2 presents average coefficient estimates from the outlined firm-level cross-sectional regression setting for the standard, MAX, and MIN momentum strategies along with difference-of-means tests to assess whether the strategies produce significantly different 


\section{Chapter 2 Separating Momentum from Reversal in International Stock Markets}

momentum profits. The last row provides the economic and statistical significance of the average return premiums associated with the three strategies based on the difference between the long and short leg coefficient estimates.

To begin with, specification (1) reports the results for the standard momentum strategy. As indicated by the average coefficient estimates on Long and Short, past winners are associated with significantly positive subsequent returns $(1.74 \%$ per year), while past losers are associated with subsequent negative returns (-1.83\% per year). Though the strategy's shortleg return is statistically somewhat weaker over the sample period, the spread in average returns is sufficient to obtain a significant (long-short) standard momentum premium of $3.57 \%$ per year after controlling for firm size, book-to-market, operating profitability, and investment.

Specifications (2) and (3) report the results for the novel MAX and MIN strategies. When the MAX strategy is considered, where the long leg consists of winners with high expected return characteristics (small and value) and the short leg is based on losers with low expected return characteristics (large and growth), the attainable momentum premium is economically and statistically greatly enhanced and amounts now to more than $7.34 \%$ per year. The average return premium is here equally driven by the strategy's long leg (3.63\% per year) as well as by the short leg $(-3.70 \%$ per year). In contrast, when the MIN strategy is considered, where the long leg consists of winners with low expected return characteristics (large and growth) and the short leg is based on losers with high expected return characteristics (small and value), the attainable momentum premium is with its value of $1.20 \%$ per year statistically not reliably different from zero.

Comparing our international results to the previous U.S. evidence in Conrad and Yavuz (2017) indicates, in general, a similar return behavior across equity markets. In a related analysis that also controls for the Fama and French (2015) benchmark variables, they report significant MAX momentum premiums of $1.01 \%$ per month over the strategy's first six months and $0.59 \%$ per month over the subsequent six-month period, which correspond to 


\section{Chapter 2 Separating Momentum from Reversal in International Stock Markets}

about $10.03 \%$ on an annual basis (formally, $\left.(1+0.0101)^{6} \times(1+0.0059)^{6}-1\right)$ over their 1965 2010 sample period. For the MIN strategy, they report insignificant premiums of $0.11 \%$ per month over the first six months and $-0.23 \%$ over the following six months, which correspond on average to $-0.72 \%$ per year.

The estimates on the control variables echo in general prior results in the literature and corroborate their importance as cross-sectional return determinants in non-U.S. equity markets. International stock returns are significantly positively associated with book-tomarket and operating profitability, while they are significantly negatively related to investment. In contrast, we do not find that firm size has significant power predicting returns during the sample period. This result is, however, also in line with recent international evidence (e.g., Fama and French, 2012, 2017).

The difference-of-means tests in the last three columns show that the average return premiums associated with the MAX and MIN strategies are significantly different from the standard momentum premium and to each other. Relative to the standard strategy, the return spread between winners and losers is noticeably more pronounced when small value winners and large growth losers are considered (MAX), while it is less pronounced when large growth winners and small value losers constitute the strategy (MIN). Finally, the difference between the MAX and MIN momentum premiums is statistically highly significant and amounts to more than $6.14 \%$ per year.

An inspection of the individual difference-of-means tests reveals that both legs of the MAX strategy significantly contribute to its superior overall performance, regardless of which of the other two strategies is used for comparison.

Since the MAX strategy appears to be the most promising of the three from an investment perspective, we further investigate the strategies' turnover and potential transaction costs to shed light on practical implementation issues. To begin with, though momentum-based investment strategies are often implemented with monthly rebalancing in the literature, we 


\section{Chapter 2 Separating Momentum from Reversal in International Stock Markets}

primarily focus in our analysis on the performance over a twelve-month holding period to identify strategies that do not require frequent rebalancing in order to lower transaction costs. Examining the turnover (across the long and short leg portfolios) of the standard, MAX, and MIN momentum strategies in terms of unique stock additions and removals, we find on average values of $33.63 \%, 39.56 \%$, and $36.67 \%$ per year, respectively. ${ }^{5}$ However, since we study the strategies based on Fama and MacBeth (1973) regressions which are analogous to creating equal-weighted portfolios, the annual rebalancing to equal weights could potentially increase the turnover to $100 \%$ per year. ${ }^{6}$ Does this circumstance eliminate the superior performance of the MAX strategy after accounting for corresponding transaction costs?

We address this question by employing the novel insights of Frazzini et al. (2018) who have analyzed over 1.7 trillion dollars of executed trades across 21 developed equity markets over a 19-year period from AQR Capital, a large institutional asset manager that is well-known for its scientific and factor-based investing approach. Though their cost measures fully take into account bid-ask spreads, market impact costs, and commissions, they find that real-world trading costs are much smaller compared to the - typically assumed - costs used in previous studies. ${ }^{7}$ For instance, realized trading costs for long or short positions in non-U.S. stocks are on average $0.11 \%$ or $0.22 \%$ and range for small stocks from $0.23 \%$ (long) to $0.27 \%$ (short). Using for simplicity the largest magnitude of $0.27 \%$ regardless of the given order type and an annual turnover of $100 \%$, the roundtrip costs would only amount to $0.54 \%$ per year which seems negligible in light of the MAX strategy's abnormal return of $7.34 \%$ per year.

Up to this point, our full sample results fall right in line with our first hypothesis. To further assess the robustness of our findings across time, firm size, and regions, we repeat our cross-

\footnotetext{
5 These magnitudes are similar to the average turnover of value-weighted U.S. momentum strategies (34.5\%) that do not rebalance stocks to initial weights (Novy-Marx and Velikov, 2016).

6 Jegadeesh and Titman (1993) find that even when equal-weighted portfolios are used for momentum strategies, the average turnover is usually less than $100 \%$. They report an average value of $84.8 \%$ on their strategy.

7 The most important determinant of trading costs is the price impact, as bid-ask spreads and trading commissions do not scale with trading size.
} 
sectional regression analysis for the MAX and MIN strategies in two different sub-periods, among small and large firms, and in three different regions (Asia-Pacific, Europe, and Japan). The corresponding results are presented in Table 2.3, where Panel A shows estimates for the MAX strategy and Panel B shows estimates for the MIN strategy.

Table 2.3 Robustness of MAX and MIN momentum strategies

Panel A: MAX momentum strategy

\begin{tabular}{|c|c|c|c|c|c|c|c|}
\hline Specification & (1) & (2) & (3) & (4) & (5) & (6) & (7) \\
\hline Sample & All & All & Small & Large & Asia-Pac & Europe & Japan \\
\hline Period & Earlier & Later & Full & Full & Full & Full & Full \\
\hline \multirow[t]{2}{*}{ Long } & 3.67 & 3.59 & 3.19 & 2.04 & 1.99 & 4.34 & -1.01 \\
\hline & $(3.25)$ & $(4.26)$ & $(3.49)$ & $(2.15)$ & (0.99) & $(4.08)$ & $(-1.41)$ \\
\hline \multirow[t]{2}{*}{ Short } & -2.53 & -4.87 & -3.70 & -2.66 & -7.48 & -4.87 & -0.39 \\
\hline & $(-1.67)$ & $(-3.17)$ & $(-3.43)$ & $(-2.35)$ & $(-4.61)$ & $(-3.36)$ & $(-0.42)$ \\
\hline \multirow[t]{2}{*}{ SZ } & 0.02 & -0.17 & -1.70 & 0.57 & -1.59 & 0.28 & -0.14 \\
\hline & $(0.05)$ & $(-0.92)$ & $(-4.53)$ & $(1.94)$ & $(-2.51)$ & (1.07) & $(-0.38)$ \\
\hline \multirow[t]{2}{*}{ BM } & 3.64 & 1.93 & 2.29 & 3.59 & 3.91 & 3.27 & 4.87 \\
\hline & (3.59) & $(4.29)$ & $(4.56)$ & $(4.08)$ & (3.70) & $(3.93)$ & (5.32) \\
\hline \multirow[t]{2}{*}{$\mathrm{OP}$} & 1.38 & 1.72 & 1.44 & 1.57 & 6.00 & 1.44 & 1.02 \\
\hline & $(6.00)$ & $(7.78)$ & (7.32) & $(7.34)$ & $(4.66)$ & $(6.30)$ & $(5.04)$ \\
\hline \multirow[t]{2}{*}{ INV } & -3.25 & -2.40 & -2.81 & -1.88 & -2.29 & -2.96 & 5.57 \\
\hline & $(-2.88)$ & $(-5.48)$ & $(-4.10)$ & $(-2.45)$ & $(-2.34)$ & $(-3.73)$ & $(1.41)$ \\
\hline $\mathrm{R}^{2}$ & 0.16 & 0.10 & 0.14 & 0.16 & 0.05 & 0.03 & 0.04 \\
\hline \multirow[t]{2}{*}{ Long-Short } & 6.20 & 8.47 & 6.89 & 4.70 & 9.48 & 9.21 & -0.61 \\
\hline & $(2.55)$ & $(3.77)$ & $(4.01)$ & $(2.46)$ & (2.97) & $(3.93)$ & $(-0.46)$ \\
\hline
\end{tabular}


Chapter 2 Separating Momentum from Reversal in International Stock Markets

Panel B: MIN momentum strategy

\begin{tabular}{|c|c|c|c|c|c|c|c|}
\hline Specification & (1) & (2) & (3) & (4) & (5) & (6) & (7) \\
\hline Sample & All & All & Small & Large & Asia-Pac & Europe & Japan \\
\hline Period & Earlier & Later & Full & Full & Full & Full & Full \\
\hline \multirow[t]{2}{*}{ Long } & 1.51 & 1.79 & 0.90 & 0.89 & 3.99 & 2.62 & -1.94 \\
\hline & $(0.86)$ & $(1.38)$ & $(0.90)$ & $(0.89)$ & (2.58) & $(2.24)$ & $(-1.67)$ \\
\hline \multirow[t]{2}{*}{ Short } & -0.41 & 1.32 & 0.55 & -0.86 & 1.44 & -1.40 & 0.81 \\
\hline & $(-0.31)$ & $(1.47)$ & $(0.48)$ & $(-0.85)$ & $(0.66)$ & $(-1.25)$ & $(1.00)$ \\
\hline \multirow[t]{2}{*}{ SZ } & -0.22 & -0.36 & -2.02 & 0.36 & -1.83 & -0.00 & -0.04 \\
\hline & $(-0.62)$ & $(-2.00)$ & $(-6.01)$ & $(1.41)$ & $(-3.01)$ & $(-0.02)$ & $(-0.11)$ \\
\hline \multirow[t]{2}{*}{$\mathrm{BM}$} & 4.37 & 2.15 & 2.69 & 4.06 & 4.08 & 3.98 & 4.50 \\
\hline & $(4.56)$ & $(3.95)$ & $(5.17)$ & (4.59) & (3.67) & $(4.51)$ & $(4.86)$ \\
\hline \multirow[t]{2}{*}{$\mathrm{OP}$} & 1.37 & 1.69 & 1.44 & 1.54 & 5.66 & 1.40 & 1.04 \\
\hline & $(5.86)$ & $(7.89)$ & $(7.25)$ & $(7.20)$ & (4.34) & $(6.18)$ & $(5.12)$ \\
\hline \multirow[t]{2}{*}{ INV } & -3.38 & -2.50 & -2.91 & -1.94 & -2.52 & -3.12 & 5.36 \\
\hline & $(-3.04)$ & $(-5.65)$ & $(-4.27)$ & $(-2.53)$ & $(-2.49)$ & $(-3.94)$ & (1.39) \\
\hline $\mathrm{R}^{2}$ & 0.16 & 0.10 & 0.14 & 0.16 & 0.05 & 0.03 & 0.05 \\
\hline \multirow[t]{2}{*}{ Long-Short } & 1.93 & 0.47 & 0.35 & 1.75 & 2.55 & 4.03 & -2.74 \\
\hline & $(0.90)$ & $(0.24)$ & $(0.24)$ & $(1.06)$ & $(1.22)$ & $(2.02)$ & $(-1.72)$ \\
\hline
\end{tabular}

This table presents average coefficient estimates and associated Newey-West adjusted $t$-statistics (in parentheses) from monthly firm-level cross-sectional regressions. The dependent variable is the firm's future twelve-month stock return. See Table 2.2, for a description of the independent variables. $\mathrm{R}^{2}$ is adjusted for degrees of freedom. The last row provides the average return premium associated with the given strategy in percent per year based on the difference between the long and short leg coefficient estimates. The earlier and later half samples cover July 1990 to December 2003 and January 2004 to June 2017, respectively. The small (large) sub-sample consists of the bottom (top) $50 \%$ of firms in each country in terms of market equity, measured as of June of each year. Asia-Pac includes Australia, Hong Kong, New Zealand, and Singapore. With the exception of Japan, Europe encompasses the remaining sample countries (see Panel A of Table 2.1).

Specifications (1) and (2) report sub-period results. The earlier sub-period runs from July 1990 to December 2003 (162 months), while the later sub-period is from January 2004 to June 2017 (162 months). As documented by the average return premiums on the MAX and MIN strategies, the influence of the expected return characteristics on the realized momentum profits is persistent in the earlier and more recent half of the sample period. The MAX 


\section{Chapter 2 Separating Momentum from Reversal in International Stock Markets}

momentum premium is large and significantly present in both sub-periods, while the MIN momentum premium remains insignificant across time.

A further cause for concern for anomalous return patterns is their pervasiveness across size. Though we control for a possible size effect in the cross-section of average returns by including firm size as one of the control variables, it is interesting to know whether our main findings hold across small firms as well as large firms. To address this question, specifications (3) and (4) report size-segmented sub-sample results. ${ }^{8}$ The sub-sample of small (large) firms consists of the bottom (top) $50 \%$ of firms in each country in terms of market equity, measured as of June of each year. Though the MAX momentum premium is somewhat more pronounced among smaller firms, as it is the case for most other return anomalies, it is not limited to small firms but also significantly present among the largest and economically most important firms in international equity markets. In contrast, we do not find that the MIN strategy produces significant momentum profits among small firms or large firms.

Finally, specifications (5) to (7) provide regional evidence by dividing the EAFE international sample into three major regions in line with Fama and French $(2012,2017)$. Asia-Pacific includes Australia, Hong Kong, New Zealand, and Singapore. With the exception of Japan, which represents a region of its own, Europe encompasses the remaining sample countries (see Panel A of Table 2.1). We observe that the MAX momentum premium is strong in terms of economic and statistical significance among Asian-Pacific and European equity markets. On the other hand, we do not find that taking into account expected return characteristics like firm size and book-to-market in the selection of winners and losers

\footnotetext{
8 To be consistent with the intended size segmentation, the MAX and MIN strategies use tercile classifications based on the SZ, BM, and MOM distributions among the bottom or top 50\% of firms and not across all sample firms.
} 


\section{Chapter 2 Separating Momentum from Reversal in International Stock Markets}

produces significant momentum profits in Japan. ${ }^{9}$ This result is, however, consistent with Asness (2011) and others who have documented that momentum-based investment strategies do not seem to work among Japanese firms. The regional results for the MIN strategy corroborate in general our international cross-country findings of insignificant momentum profits on this type of strategy. The only exception is Europe, where the MIN momentum premium tends to be statistically significant, but in terms of its economic magnitude, it is still less than half of the corresponding European MAX momentum premium.

After having addressed the robustness of our main findings across time, firm size, and regions, we further study the MAX and MIN momentum premiums conditional upon business conditions. It is well known that the profits of momentum strategies vary with the general state of the economy. They tend to be large during expanding/optimistic states and small during contracting/pessimistic states (Jegadeesh and Titman, 2011). To address whether the MAX and MIN strategies conform to the same pattern observed for standard momentum strategies, we estimate firm-level cross-sectional regressions based on equation (1) for two different specification variants that differ in the underlying state of the economy, i.e., contracting/pessimistic versus expanding/optimistic. We measure the two economic states using six different proxies based on market volatility, market states, investor sentiment, market liquidity, default spread, and the NBER recession indicator. The first two measures are based on international EAFE data, while the remaining measures are based on U.S. data in lack of appropriate cross-country proxies. The use of U.S.-based variables outside the

9 In light of this finding, we also have tested whether Japanese firms are influential in our inference that the MAX strategy is superior to the MIN strategy in international equity markets. For instance, the weighting of Japanese firms in the international MAX and MIN strategies could be responsible for the observed return difference. First, the average share of Japanese firms in the long leg portfolios is with values of $25.99 \%$ (MAX) and $25.09 \%$ (MIN) very similar across the two strategies. Only the short leg portfolios show on average a greater exposure to Japanese firms for the MAX strategy of $37.98 \%$ in comparison to $25.16 \%$ for the MIN strategy. Second, replicating the performance analysis for the MAX and MIN strategies in an international sample that excludes Japan (EAFE ex Japan) in analogy to Table 2, yields an average MAX momentum premium of $10.23 \%$ per year ( $t$-statistic of 4.45 ) and an average MIN momentum premium of $2.24 \%$ per year ( $t$-statistic of 1.32 ). Thus, the lack of momentum profits among Japanese firms cannot account for the inference that the MAX strategy is superior to the MIN strategy. 


\section{Chapter 2 Separating Momentum from Reversal in International Stock Markets}

United States can be motivated by Baker et al. (2012) who show that sentiment is contagious across countries and particularly driven by the U.S. sentiment. Furthermore, Rapach et al. (2013) document that the United States possesses, as the world's largest and most important equity market, a leading role for international markets.

The proxies are defined as follows. Market volatility is the annual standard deviation of the value-weighted EAFE market portfolio returns over the 12 months prior to the beginning of the strategies' holding period (Baker and Wurgler, 2006). Following Cooper et al. (2004), the market state is measured based on the cumulative return on the value-weighted EAFE market portfolio over the 36 months prior to the beginning of the strategies' holding period. To capture investor sentiment, we rely on the monthly U.S. sentiment index constructed by Baker and Wurgler (2006). ${ }^{10}$ To measure market liquidity, we employ Hu et al.'s (2013) noise index, which is based on the aggregate noise in the prices of U.S. Treasury bonds, i.e., the differences between market and model-implied yields. ${ }^{11}$ In light of the fact that the U.S. Treasury bond market is one of the most active and liquid markets in the world and one with the highest credit quality, the level of noise in this market can be used as a market-wide measure of liquidity. In line with Fama and French (1993), the default spread is the monthly difference between the yield on an index of 10-year U.S. corporate bonds and 10-year U.S. Treasury bonds. ${ }^{12}$ Finally, the NBER recession indicator for the United States is used to separate crisis from non-crisis periods over the sample period. Except for market states and the NBER recession indicator, the median of the given economic state proxy over the sample period is used to define periods of low and high values on that measure. Positive (negative) 36-month market returns separate up (down) market states.

\footnotetext{
${ }^{10}$ The sentiment index is available at Jeffrey Wurgler's website: http://pages.stern.nyu.edu/ jwurgler/. The index time series runs until September 2015.

${ }^{11}$ The noise index is available at Jun Pan's website: http://www.mit.edu/ junpan/. The index time series runs until December 2016. The data is provided on a daily basis. We employ the index's daily end-of-month values for our analysis.

${ }^{12}$ An appropriate U.S. corporate bond index is available in Datastream from April 2002 on.
} 


\section{Chapter 2 Separating Momentum from Reversal in International Stock Markets}

Figure 2.1 illustrates the average return premiums associated with the standard, MAX, and MIN momentum strategies during contracting/pessimistic business conditions (black bars) and expanding/optimistic business conditions (clear bars), as measured by the six different economic state proxies (Panels A to F). As before, the premiums are derived from the differences between the long and short leg coefficient estimates from the outlined firm-level cross-sectional regression setting that includes common return controls and country dummies.

First, regardless of the applied economic state proxy, the standard and MAX strategies are associated with significantly positive average return premiums during expanding/optimistic periods. Across the six proxies, the average momentum profits here amount to $5.56 \%$ per year on the standard strategy and $9.57 \%$ per year on the MAX strategy. During contracting/pessimistic periods, we do, however, not find that the standard and MAX momentum premiums are statistically significantly different from zero. The MIN momentum premium is in general insignificant in both states of the economy. The only two exceptions, where we find significantly positive momentum profits on this type of strategy are periods of low market volatility and after positive 36-month market returns (up markets).

Second, conducting difference-of-means tests on the strategies' average momentum profits during a given economic state corroborates our previous inference on the superiority of the MAX strategy. Regardless of the applied economic state proxy and irrespective of the given economic state, the differences between the MAX and standard momentum premiums are always significantly positive and statistically significant. The same is true for the differences between the MAX and MIN momentum premiums. Hence, the MAX strategy is superior in comparison to the standard and MIN momentum strategies during contracting/pessimistic as well as expanding/optimistic periods. Comparing the MIN strategy relative to the standard strategy, we observe that the differences in premiums are persistently significantly negative during expanding/optimistic periods, while they are in general insignificant during contracting/pessimistic periods. 
Chapter 2 Separating Momentum from Reversal in International Stock Markets

Figure 2.1 Momentum premiums conditional upon business conditions

Panel A: Market volatility

- High Volatility $\square$ Low Volatility

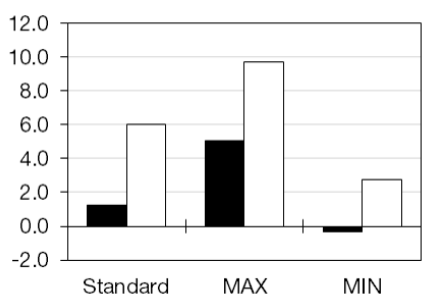

Panel C: Investor sentiment

- Low Sentiment $\square$ High Sentiment

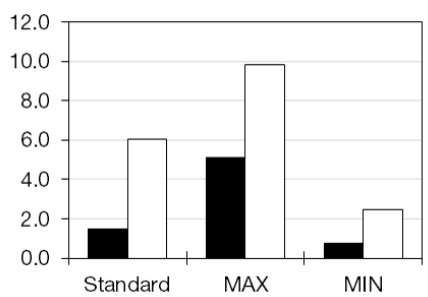

Panel E: Default spread

- High Spread aLow Spread

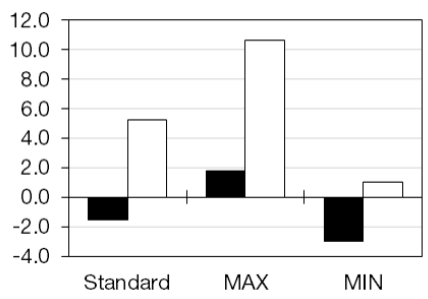

Panel B: Market states

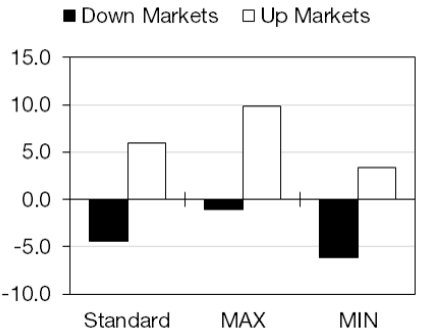

Panel D: Market liquidity

- Illiquid Markets aLiquid Markets

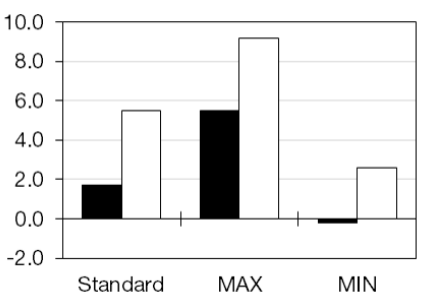

Panel F: NBER recession indicator

- Crisis $\square$ Non-Crisis

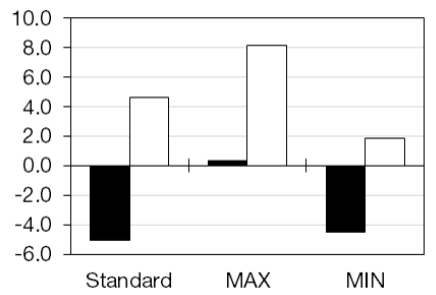

This figure illustrates the average return premiums associated with the standard, MAX, and MIN strategies in percent per year during contracting/pessimistic business conditions (black bars) and expanding/optimistic business conditions (clear bars), as measured by six different economic state proxies (Panels A to F). 


\section{Chapter 2 Separating Momentum from Reversal in International Stock Markets}

In sum, the results in this section are consistent with hypothesis H1. Similar to the prior U.S. evidence, we observe that the MAX strategy produces significantly larger benchmarkadjusted returns than the MIN strategy and the standard momentum strategy in non-U.S. equity markets over holding periods up to one year.

\subsection{Longer holding period returns}

Following the insights of Conrad and Yavuz (2017), we test in this section hypothesis H2 that the MAX strategy displays no return reversal, while the MIN strategy exhibits significant return reversal over holding periods beyond one year. To explore whether their U.S. findings carry over to international equity markets, we estimate different firm-level cross-sectional regressions nested within equation (1), where the dependent variable now is the longer holding period return computed over the second and third year after the measurement of the strategies' underlying firm characteristics.

Table 2.4 presents average coefficient estimates from the outlined firm-level cross-sectional regression for the two year-to-year holding periods. The results document that selecting winners and losers conditional upon their expected return characteristics based on firm size and book-to-market also has a major impact on the behavior of longer holding period returns.

While the MAX strategy yields strong momentum profits in the first year (see Table 2.2), it does not display significant return reversals in the following two years. The average coefficient estimates on Long and Short as well as the resulting (long-short) MAX momentum premium are all statistically indistinguishable from zero. This is in sharp contrast to the MIN strategy which does not produce significant momentum profits in the first year but suffers from substantial return reversals in the subsequent years. The average MIN momentum premium is $-4.83 \%$ per year in the second year and $-3.70 \%$ in the third year. As indicated by significantly positive short-leg returns, the reversal is primarily driven by the rebound of the strategy's short leg that generates benchmark-adjusted returns of around $3 \%$ per year. 
Chapter 2 Separating Momentum from Reversal in International Stock Markets

Table 2.4 Longer holding period returns of MAX and MIN momentum strategies

\begin{tabular}{lcccc}
\hline & \multicolumn{2}{c}{ MAX momentum strategy } & \multicolumn{2}{c}{ MIN momentum strategy } \\
\hline $\begin{array}{l}\text { Specification } \\
\text { Return }\end{array}$ & $(1)$ & $(2)$ & $(1)$ & $(2)$ \\
\hline \multirow{2}{*}{ Long } & 2nd Year & 3rd Year & 2nd Year & 3rd Year \\
& -0.71 & -0.81 & -1.45 & -1.00 \\
Short & $(-1.08)$ & $(-1.06)$ & $(-1.86)$ & $(-1.50)$ \\
& 0.12 & 0.72 & 3.38 & 2.70 \\
SZ & $(0.11)$ & $(0.74)$ & $(4.85)$ & $(4.11)$ \\
& -0.25 & -0.14 & -0.13 & -0.02 \\
BM & $(-1.18)$ & $(-0.71)$ & $(-0.64)$ & $(-0.12)$ \\
& 2.14 & 1.81 & 1.81 & 1.54 \\
OP & $(3.81)$ & $(3.15)$ & $(3.32)$ & $(2.98)$ \\
& 1.18 & 1.09 & 1.18 & 1.10 \\
INV & $(7.17)$ & $(5.74)$ & $(7.21)$ & $(5.82)$ \\
& -1.73 & -0.83 & -1.72 & -0.75 \\
& $(-3.20)$ & $(-1.30)$ & $(-3.16)$ & $(-1.18)$ \\
$\mathrm{R}^{2}$ & & & & \\
& 0.13 & 0.13 & 0.13 & 0.13 \\
Long-Short & -0.84 & -1.52 & -4.83 & -3.70 \\
& $(-0.52)$ & $(-1.13)$ & $(-4.13)$ & $(-3.59)$ \\
\hline
\end{tabular}

This table presents average coefficient estimates and associated Newey-West adjusted $t$-statistics (in parentheses) from monthly firm-level cross-sectional regressions. The dependent variable is the firm's second-year or third-year return after the measurement of the strategies' underlying firm characteristics. See Table 2.2, for a description of the independent variables. $\mathrm{R}^{2}$ is adjusted for degrees of freedom. The last row provides the average return premium associated with the given strategy in percent per year based on the difference between the long and short leg coefficient estimates.

Taken together, the results in this section strongly support hypothesis H2. Short-term return continuation and long-term return reversals are not necessarily linked. Taking into account expected return characteristics like firm size and book-to-market in the selection of winners and losers helps to ex ante separate momentum stocks that display return reversals from those that do not. 
Chapter 2 Separating Momentum from Reversal in International Stock Markets

\subsection{A mispricing-based explanation}

In this section, we test our final hypothesis $\mathrm{H} 3$ that the strong performance of the MAX strategy and the weak performance of the MIN strategy are the outcome of mispricing. Even though Conrad and Yavuz (2017) argue in favor of a risk-based explanation, they do not rule out the possibility that the varying MAX and MIN momentum premiums may be attributable to cross-sectional mispricing. In particular, they only study whether the U.S. premiums are related to market states and investor sentiment. Lagged market returns and the investor sentiment index are commonly used as market-wide proxies for mispricing that reflect aggregate investor confidence or risk aversion which may cause delayed overreaction among investors and therefore provide an explanation for the observed momentum pattern in average stock returns. However, both explanations fall short to explain the MAX and MIN momentum premiums. Though the level of market-wide mispricing may explain the varying strength of the momentum premium across time, existing mispricing at one point in time can also vary across firms (Hirshleifer and Jiang, 2010; Walkshäusl, 2016).

Following this reasoning, we explicitly investigate the aspect of cross-sectional mispricing as an explanation for the significantly different return behavior of the MAX and MIN strategies. To proxy for systematic mispricing, we employ the firm's external financing behavior as measured by Bradshaw et al.'s (2006) XFIN variable. Positive values on XFIN indicate issues, while negative values indicate repurchases. The opportunistic financing hypothesis (Ikenberry et al., 1995; Loughran and Ritter, 1995) suggests that firms issue additional capital when prices are high and repurchase outstanding capital when prices are low. Thus, issues (repurchases) provide signals of potential overvaluation (undervaluation) based on the management's private assessment of the firm's intrinsic value relative to the market. Thus, if cross-sectional mispricing drives the return behavior of the MAX and MIN strategies, the realized momentum profits on the two strategies should consequently differ when the underlying momentum stocks are either perceived as overvalued or undervalued. 


\section{Chapter 2 Separating Momentum from Reversal in International Stock Markets}

To examine whether the observed return premiums on the MAX and MIN strategies are attributable to the systematic exploitation of cross-sectional mispricing, we estimate firmlevel cross-sectional regressions based on equation (1) for two different specification variants that differ in their underlying stock samples. Specification (1) excludes winners that are also issuers and losers that are also repurchasers, thus, representing overvalued winners and undervalued losers. Specification (2) excludes winners that are also repurchasers and losers that are also issuers, thus, denoting undervalued winners and overvalued losers. The firms excluded from the corresponding samples are identified each month by their monthlyupdated MOM characteristic and their XFIN characteristic which is measured each June. By constraining the underlying stock samples in this way, we obtain groups of firms, where the perceived mispricing of winners and losers is in general favorable (specification (1)) or unfavorable (specification (2)) for momentum strategies that exploit cross-sectional mispricing.

Table 2.5 presents average coefficient estimates from the two outlined firm-level crosssectional regression variants using holding period returns computed over the first, second, and third year after the measurement of the strategies' underlying firm characteristics. Panel A shows estimates for the MAX strategy and Panel B shows estimates for the MIN strategy. For the sake of brevity, the estimates on the common control variables are not tabulated.

The results document that cross-sectional mispricing plays an important role in understanding the return behavior of MAX and MIN strategies. In line with our previous findings, the MAX strategy produces a significantly positive momentum premium in the first year and no significant return reversals in the following two years when the unfavorablymispriced winners and losers are excluded from the sample (specification (1)). However, this inference changes considerably when the favorably-mispriced winners and losers are left out. In specification (2), the MAX momentum premium is rendered insignificant in the first year, and the strategy now suffers from substantial return reversals in the second and third year. 
Chapter 2 Separating Momentum from Reversal in International Stock Markets

Table 2.5 Returns to MAX and MIN momentum strategies conditional on mispricing

\begin{tabular}{lcccccc}
\hline Specification & \multicolumn{3}{c}{$(1)$} & \multicolumn{3}{c}{$(2)$} \\
\hline Excluding & \multicolumn{3}{c}{ Overvalued winners \& } \\
& undervalued losers & \multicolumn{3}{c}{ Undervalued winners \& } \\
overvalued losers
\end{tabular}

This table presents average coefficient estimates and associated Newey-West adjusted $t$-statistics (in parentheses) from monthly firm-level cross-sectional regressions. The dependent variable is the firm's first-year, second-year or third-year return after the measurement of the strategies' underlying firm characteristics. The common control variables are untabulated, see Table 2.2, for a description. The sample in specification (1) excludes overvalued winners and undervalued losers, while the sample in specification (2) excludes undervalued winners and overvalued losers. Misvaluation is identified by the firm's external financing behavior, where negative values on XFIN denote undervaluation and positive values on XFIN denote overvaluation. $\mathrm{R}^{2}$ is adjusted for degrees of freedom. The last row provides the average return premium associated with the given strategy in percent per year based on the difference between the long and short leg coefficient estimates. 


\section{Chapter 2 Separating Momentum from Reversal in International Stock Markets}

Analogously, the previously found poor performance of the MIN strategy turns strong when the unfavorably-mispriced winners and losers are excluded from the sample, as done in specification (1). The strategy then yields significantly positive momentum profits in the first year and exhibits no significant return reversals in the subsequent years. In contrast, when the favorably-mispriced winners and losers are discarded in specification (2), the MIN strategy reveals its weak performance with strong return reversals in the second and third year.

Taken together, the results in this section strongly support hypothesis H3. The realization of the superior performance on the MAX strategy and the occurrence of the inferior performance on the MIN strategy is strongly dependent on cross-sectional mispricing. The varying performance of the MAX and MIN strategies among favorably-mispriced and unfavorably-mispriced winners and losers furthermore suggests that firm size and book-tomarket may rather be proxies for cross-sectional mispricing than risk-based expected return characteristics.

\subsection{Conclusion}

In this paper, we test the U.S. findings of Conrad and Yavuz (2017) that stocks with momentum can be ex ante separated from those that exhibit reversal by taking into account characteristics like firm size and book-to-market in the selection of winners and losers. We provide strongly supportive out-of-sample evidence on the previous U.S. findings in the broad cross-section of international firms drawn from 20 developed non-U.S. equity markets over the sample period from 1990 to 2017.

A strategy that buys small value winners and sells large growth losers, denoted the MAX strategy, generates significantly larger momentum profits than a standard momentum strategy, is robust to common return controls, and does not suffer from return reversals for holding periods up to three years. In contrast, a strategy that buys large growth winners and sells small value losers, denoted the MIN strategy, produces no significant momentum profits 
but significant return reversals over holding periods beyond one year. Consistent with the view that firm size and book-to-market can also be interpreted as measures of mispricing, the significantly different return behavior of the MIN and MAX strategies is attributable to a rather systematic exploitation of cross-sectional mispricing among momentum stocks. The superior performance of the MAX strategy is driven by undervalued winners and overvalued losers, while the inferior performance of the MIN strategy is driven by the fact that the strategy's underlying stock selection procedure picks overvalued winners and undervalued losers. 


\title{
Chapter 3
}

\section{Continuing Overreaction: European Evidence}

This research project is joint work with Ulrich Wessels. The paper has been submitted to the Quarterly Review of Economics and Finance and is currently under review.

\begin{abstract}
This paper tests Byun, Liam and Yun (2016) continuing overreaction measure using weighted signed volumes in European equity markets. As in the U.S., firms with high measures of continuing overreaction outperform firms with low measures. The observed premium is even higher than within a standard momentum approach and does not suffer from return reversal for holding periods up to three years. Furthermore, the observed premium is robust to common controls, such as firm size, book-to-market and momentum, as well as more recent controls for investment and operating profitability. Within different business conditions, the novel measure has a clear superiority towards momentum especially during contracting/pessimistic periods.
\end{abstract}

Keywords Momentum; Trading volume; Return predictability; Continuing overreaction; International markets 


\section{Chapter 3 Continuing Overreaction: European Evidence}

\subsection{Introduction}

It is well established that overconfidence can explain a broad set of anomalies all around the globe. Specifically, the research goes back to Daniel et al. (1998), who demonstrate that the overconfidence of investors and their biased self-attribution can explain overreactions as well as underreactions in international stock markets. They argue that in the course of overestimation of their own abilities investors overvalue private information and underreact to public information signals. However, if a later public signal confirms the private information thus good (bad) news supports the investor's buy (sell) decision, his confidence rises and leads to biased self-attribution. Or to put it in a simple way: past returns predict future returns, and as a consequence short-run momentum and long-term reversals arise. ${ }^{1}$

Building upon the insight that continuing overreaction causes momentum in the short run, Byun et al. (2016) construct a completely novel measure of continuing overreaction (CO hereafter). They argue if CO causes momentum as argued by Daniel et al. (1998) a more direct $\mathrm{CO}$ measure can predict future returns better than past returns and the results are even stronger within stocks held primarily by investors leaning towards biased self-attribution. To calculate the continuing overreaction measure they use weighted signed volumes and the direction of investor's overreaction indicated by the sign of stock returns.

The results of Byun et al. (2016) are interesting especially for two reasons. First, the premium based on the innovative continuing overreaction measure is economically significant and actually larger than the premium of a standard momentum approach. The $\mathrm{CO}$ premium stays significant even when they control for momentum while inversely momentum disappears when $\mathrm{CO}$ is taken into account. In addition, in line with prior momentum literature (e.g., Asness, 2011) they cannot find significant CO premium for the Japanese equity market due to missing biased self-attribution. Second, Byun et al. (2016) provide a direct support of the

\footnotetext{
1 For the well-known momentum effect on the U.S. equity market see Jegadessh and Timan $(1993,2001)$ and e.g., Rouwenhorst (1998), Chui et al. (2010) or Asness et al. (2013) for non-U.S. evidence.
} 


\section{Chapter 3 Continuing Overreaction: European Evidence}

Daniel et al. (1998) model that overconfidence and biased self-attribution leads to overreactions and a better estimation of stock return predictability.

A broad set of literature already demonstrated theoretical evidence that overconfidence leads to higher trading volume. Odean (1998) demonstrates that trading volume increases when investors are overconfident and described it as the most robust effect of overconfidence. ${ }^{2}$ Barber and Odean (2001) provide empirical evidence that men are more overconfident than women are and thus trade more excessively. Furthermore, Statman et al. (2006) also find supporting evidence on the theoretical models of higher trading volume as a result of biased self-attribution by Gervais and Odean (2001). ${ }^{3}$

Byun et al. (2016) argue that trading volume can be used as a proxy for overconfidence, but the trading volume itself does not predict future stock returns, because the direction of overreaction is not known. Therefore, they multiply the trading volume with the sign of the average stock return in the given time period. Specifically, if the stock return is negative (positive) the signed volume has a negative (positive) sign as well. Additionally, Byun et al. (2016) take the weighted sum of signed volumes and simultaneously give a larger weight the more recent the signed volume is to the point where $\mathrm{CO}$ is calculated. ${ }^{4} \mathrm{As}$ a consequence, the novel CO measure displays a trend of investors overconfidence in the examined time.

Given that the study mentioned above mainly focuses on the U.S. equity market, but momentum and continuing overreaction is also present outside the USA (Rouwenhorst, 1998; Chui et al., 2010; Fama and French, 2012; Asness et al., 2013), we contribute in the present paper to the literature by studying the novel $\mathrm{CO}$ measure in European equity markets for the first time. As with any finding in empirical research, the $\mathrm{CO}$ measure could be the result of data snooping in the sense of Lo and MacKinlay (1990) and therefore be sample specific. Given that empirical financial research mostly focuses on the U.S. market (Karolyi, 2016),

\footnotetext{
2 Benos (1998) also exhibits a theoretical model where the trading volume increases with the number of overconfident traders in the stock market.

3 For further empirical evidence see e.g., Glaser and Weber (2009) and Grinblatt and Keloharju (2009).

4 Statman et al. (2006) also use signed volume and examine it within a time series test setting.
} 
testing former U.S. results in non-U.S. markets is important to enhance the quality of the return predictability literature as well as to guard against data snooping. To address this concern, we independently examine in this study the relation between $\mathrm{CO}$ measures and subsequent stock returns in the broad cross-section of European firms drawn from 15 developed non-U.S. equity markets. As European equity markets provide fresh data, our nonU.S. analysis provides a useful out-of-sample test on the significance of the $\mathrm{CO}$ measure around the world.

Following the previous U.S. evidence, we develop three hypotheses that we test out-ofsample in foreign European equity markets. The first hypothesis addresses whether European stock market returns sorted on the innovative $\mathrm{CO}$ measure conform to the same pattern observed in the United States.

Hypothesis 1: A significantly positive relation exists between the firm's continuing overreaction measure and subsequent stock returns.

Showing that a positive return relation exists between firms with high $\mathrm{CO}$ measures and firms with low $\mathrm{CO}$ does, however, not rule out the possibility that the identified return behavior is simply a manifestation of already known return effects. Therefore, we examine in the second hypothesis whether the return effect is pervasive in the presence of various return predictors.

Hypothesis 2: The return difference between firms with the strongest $\mathrm{CO}$ measure and firms with the lowest CO measure is not subsumed by established cross-sectional determinants.

On the one hand, we control for the traditional return effects based on firm size and book-tomarket (Fama and French, 1992). Taking into account the most recent developments in asset pricing on the other hand, we also control for the novel benchmark variables associated with operating profitability and investment that have been proposed by Fama and French (2015) for a comprehensive description of the cross-section of average stock returns. Besides that, we also test whether a momentum factor (Jegadeesh and Titman, 1993) drives out the observed premium. 


\section{Chapter 3 Continuing Overreaction: European Evidence}

Hypothesis 3: The return premium between firms with high and low CO measures is also present within different business conditions.

As it is well known that momentum profits vary with the state of the economy, we test the $\mathrm{CO}$ measure in contracting/pessimistic business conditions and compare it to expanding/optimistic business conditions. As different measures, we use market volatility, market states, investor sentiment, market liquidity, default spread, and the NBER recession indicator.

Our results are easily summarized. Similar to the United States, the CO measure is suitable as an international measure for continuing overreaction. First, we find a significant and positive return premium between stocks with high and low $\mathrm{CO}$ measures for about one year after portfolio formation that becomes insignificant afterwards but does not turn into reversal. Second, the return premium cannot be explained by established cross-sectional determinates and even a momentum factor cannot explain the premium. Third, $\mathrm{CO}$ premium is also available during different states of the economy.

Taken together, our out-of-sample analysis strongly supports the CO measure constructed by Byun et al. (2016). The continuing overreaction measure provides a newly and more direct measure even on the European stock markets. Furthermore, the results improve the quality of literature regarding return predictability in the sense of Daniel et al. (1998) across equity markets.

The remainder of the paper is organized as follows. The next section describes the data and variables used in this study. The subsequent sections test the outlined hypotheses and present the empirical results. The final section concludes the paper. 


\subsection{Data and summary statistics}

We study a European stock market sample that consists of firms from 15 developed markets, namely: Austria, Belgium, Denmark, Finland, France, Germany, Ireland, Italy, the Netherlands, Norway, Portugal, Spain, Sweden, Switzerland, and the UK. Our sample selection mirrors the countries included in the well-known European stock market benchmark form MSCI. We collect monthly total return data on common stocks from Datastream and firm-level accounting information from Worldscope. To make sure that accounting information is known before the returns are calculated, we match the latest accounting information for the fiscal year ending in the previous year with stock returns from July of the current year to June of the subsequent year. All data are denominated in U.S. dollars. To ensure that our results are not driven by tiny or illiquid tocks, we follow Ang et al. (2009) and exclude the $5 \%$ of firms with the lowest market equity in each country. In addition, as in Fama and French (1992) firm-year observations with negative book equity are excluded from the sample as well as financial firms with Standard Industrial Classification (SIC) codes between 6000 and 6999. The sample period is from July 1990 to June 2018.

Following Byun et al. (2016) we calculate the continuing overreaction measure as follows. The signed volume $\left(\mathrm{SV}_{\mathrm{i}, \mathrm{t}}\right)$ for stock $\mathrm{i}$ in month $\mathrm{t}$ is defined as the sum of the trading volume which is the number of shares traded in month i multiplied by the stock price. Furthermore, $r_{i, t}$ is the stock return for firm $\mathrm{i}$ in the given month $\mathrm{t}$.

$$
\mathrm{SV}_{\mathrm{i}, \mathrm{t}}= \begin{cases}\mathrm{TV}_{\mathrm{i}, \mathrm{t}} & \text { if } r_{i, t}>0, \\ 0 & \text { if } r_{i, t}=0, \\ -\mathrm{TV}_{\mathrm{i}, \mathrm{t}} & \text { if } r_{i, t}<0\end{cases}
$$

To calculate CO, in line with Byun et al. (2016) we assign increasing weights to signed volumes that means the more recent a month the higher the weight of the signed volume. In detail, as we use a 1-year formation period for $\mathrm{CO}$ calculation throughout the paper, the 


\section{Chapter 3 Continuing Overreaction: European Evidence}

weight for the most recent month is 12 while the penultimate month is weighted with 11 and so forth until month $\mathrm{t}-12$ that is one year ago and therefore weighted with 1 . We normalize the signed volume, taking the sum of the weighted values and divide it by the average trading volume over the same period of 12 months.

$$
\mathrm{CO}_{\mathrm{i}, \mathrm{t}}=\frac{\operatorname{sum}\left(\mathrm{w}_{\mathrm{j}} * \mathrm{SV}_{\mathrm{i}, \mathrm{t}-\mathrm{J}}, \ldots, \mathrm{w}_{1} * \mathrm{SV}_{\mathrm{i}, \mathrm{t}-1}\right)}{\operatorname{mean}\left(\mathrm{VOL}_{\mathrm{i}, \mathrm{t}-\mathrm{J}}, \ldots, \mathrm{VOL}_{\mathrm{i}, \mathrm{t}-1}\right)}
$$

Table 3.1 Summary statistics, 1990-2018

Panel A: Sample countries

\begin{tabular}{lrlr}
\hline Country & Firms & Country & Firms \\
\hline & & & \\
Austria & 56 & Netherlands & 109 \\
Belgium & 79 & Norway & 114 \\
Denmark & 97 & Portugal & 49 \\
Finland & 85 & Spain & 98 \\
France & 530 & Sweden & 233 \\
Germany & 523 & Switzerland & 144 \\
Ireland & 39 & United Kingdom & 1092 \\
Italy & 159 & & \\
\hline
\end{tabular}

Panel B: Variables

\begin{tabular}{crrrrr}
\hline Quintile & SIZE & BM & OP & INV & MOM \\
\hline & & & & & \\
Low CO & 798 & 0.78 & 0.83 & 0.22 & -0.19 \\
2 & 1267 & 0.75 & 0.83 & 0.19 & -0.05 \\
3 & 1430 & 0.75 & 0.86 & 0.18 & 0.08 \\
4 & 1434 & 0.75 & 0.85 & 0.17 & 0.22 \\
High CO & 937 & 0.79 & 0.88 & 0.18 & 0.49 \\
\hline
\end{tabular}

This table presents summary statistics for the countries included in the European sample and the variables used in this study. Panel A reports the average number of firms per month in each country over the sample period from July 1990 to June 2018. Panel B reports the quintiles sorted on the continuing overreaction measure. Firm size (SZ) is market equity (stock price multiplied by the number of shares outstanding) as of June of each year in million U.S. dollars. Book-to-market (BM) is the ratio of book equity to market equity at the fiscal year-end. Operating profitability (OP) is revenues minus cost of goods sold and interest expense, all divided by book equity. Investment (INV) is the annual change in total assets divided by total assets. Momentum (MOM) is the cumulative prior six-month stock return, skipping the most recent month. 
Panel A of Table 3.1 reports the total number of firm-year observations for the countries included in the European sample. On average, our sample includes 3407 firms. In line with their importance for the European stock market, the largest portion falls on the countries UK, France, and Germany.

The variables used in this study are defined as follows. A firm's size (SZ) is its stock price multiplied by the number of shares outstanding, calculated as of June of each year in million U.S. dollars. Book-to-market (BM) is the ratio of book equity to market equity at the fiscal year-end. Momentum (MOM) is the cumulative prior twelve-month stock return, skipping the most recent month (Jegadeesh and Titman, 1993). Following Fama and French (2015), investment (INV) is the annual change in total assets divided by lagged total assets. Operating profitability (OP) is revenues minus cost of goods sold and interest expense, all divided by book equity.

Panel B of Table 3.1 summarizes the distributional statistic for the variables used in this study. A typical firm in the high (low) CO quintile of our European sample has a size of 937 (798) and a book-to-market ratio of $0.79(0.78)$. Naturally, the momentum factor is much stronger $(0.49)$ in the high quintile than in the low one $(-0.19)$.

\subsection{The CO-return relation}

In this section, we test Hypothesis 1 that firms with a strong $\mathrm{CO}$ measure have higher subsequent stock returns than firms with a weak CO measure, culminating in the existence of a positive continuing overreaction-return relation. To examine how European stock returns vary with different levels of CO measure, we begin our analysis at the portfolio level. Specifically, at the end of each month, we form quintile portfolios by allocating stocks in ascending order to five groups based on their continuing overreaction measure from the previous month. Accordingly, a firm is assigned to the high (low) quintile portfolio if its CO measure is in the top (bottom) 20 percent of the CO measures. Monthly returns are calculated 


\section{Chapter 3 Continuing Overreaction: European Evidence}

for different holding periods from 1 up to 12 months after portfolio formation, portfolios are rebalanced each month.

Table 3.2 Continuing overreaction portfolios

\begin{tabular}{ccccc}
\hline Quintiles & 1 Month & $1^{\text {st }}$ Year & $2^{\text {nd }}$ Year & $3^{\text {rd }}$ Year \\
\hline Low CO & 0.09 & 0.32 & 0.71 & 0.79 \\
2 & 0.40 & 0.55 & 0.77 & 0.84 \\
3 & 0.60 & 0.72 & 0.79 & 0.84 \\
4 & 0.96 & 0.86 & 0.80 & 0.80 \\
High CO & 1.36 & 1.06 & 0.73 & 0.71 \\
& & & & \\
High - Low & 1.27 & 0.74 & 0.02 & -0.08 \\
& $(9.37)$ & $(7.37)$ & $(0.23)$ & $(-1.00)$ \\
\hline
\end{tabular}

This table presents average monthly raw returns in percent for quintile portfolios sorted on continuing overreaction measure. The portfolios are formed every month by allocating stocks in ascending order to five groups based on their continuing overreaction measure from the previous month. The last row (High-Low) provides the average spread return between firms with high and low continuing overreaction measures. The t-statistic is given in parentheses.

Table 3.2 shows average monthly raw returns sorted on the continuing overreaction measure. The last row (High-Low) reports the spread return between firms with high and low continuing overreaction measures for testing whether the return difference is significantly different from zero. We observe that the portfolio returns ascend monotonically from firms with low $\mathrm{CO}$ to firms with high CO. For a one month holding period the H-L spread is statistically highly significant and amounts to 1.27 percent per month (t-statistic 9.37). Similar to the well-known momentum effect, we observe significant H-L returns for a holding period of up to 12 months with 0.74 percent per month (t-statistic 7.37). While momentum suffers from significant reversal after a one-year holding period, the portfolio formation on continuing overreaction displays no significant reversal even for a holding period of up to 36 months after portfolio formation. ${ }^{5}$ It is notable that the High CO portfolio

\footnotetext{
5 For the reversal effect see e.g., Jegadeesh and Titman (1993).
} 


\section{Chapter 3 Continuing Overreaction: European Evidence}

has significant positive returns for all observed holding periods. This is in sharp contrast to a standard momentum approach where the long side normally turns negative at the latest after a one-year holding period. These findings are mainly in line with Byun et al. (2016) who could not find return reversal within the U.S. equity market either.

Table 3.3 Robustness of CO measure

\begin{tabular}{ccccc}
\hline High - Low & 1 Month & $1^{\text {st }}$ Year & $2^{\text {nd }}$ Year & $3^{\text {rd }}$ Year \\
\hline & & & & \\
$(1)$ & 1.24 & 0.64 & -0.28 & -0.39 \\
Earlier & $(5.40)$ & $(3.89)$ & $(-2.06)$ & $(-3.09)$ \\
$(2)$ & 1.30 & 0.83 & 0.32 & 0.23 \\
Later & $(9.00)$ & $(7.36)$ & $(3.28)$ & $(2.46)$ \\
$(3)$ & 1.52 & 0.84 & 0.08 & -0.11 \\
Small & $(11.74)$ & $(9.01)$ & $(0.88)$ & $(-1.16)$ \\
$(4)$ & 1.11 & 0.66 & 0.02 & -0.08 \\
Large & $(6.81)$ & $(5.42)$ & $(0.16)$ & $(-0.93)$ \\
\hline
\end{tabular}

This table presents average monthly raw returns in percent and associated t-statistics (in parentheses) sorted on the continuing overreaction measure. For clarity we only show the High-Low average return spread here. The earlier and later half samples cover July 1990 to June 2004 and July 2004 to June 2018 , respectively. The small (large) sub-sample consists of the bottom (top) $50 \%$ of firms in each country in terms of market equity, measured as of June of each year.

Hitherto the results support our first hypothesis that there exists a positive relation between continuing overreaction and subsequent stock returns. To further examine the robustness of our European sample across time and firm size, we repeat our portfolio level analysis between two different sub-periods as well as between small and large firms. The corresponding results are presented in Table 3.3; for reasons of simplicity we only display the High-Low portfolio returns.

Row (1) and (2) report sub-period results. The earlier sub-period runs from July 1990 to June 2004 (168 months), while the later sub-period is from July 2004 to June 2018 (168 months). The return premium of firms with high $\mathrm{CO}$ measures was present in the earlier subsample and is even stronger in the more recent sub-period. Interestingly, while in the earlier 


\section{Chapter 3 Continuing Overreaction: European Evidence}

subsample the reversal was also present for the second and third year after portfolio formation, the subsample from 2004 to 2018 also displays a slightly significant positive return relation for longer holding periods, monthly 0.32 percent (t-statistic 3.28 ) for the second year and still 0.23 percent (t-statistic 2.46) in the third year.

A further cause for concern for anomalous return patterns is their pervasiveness across size. To address this question, rows (3) and (4) present size-segmented subsample results. The small (large) subsample consists of the bottom (top) $50 \%$ of firms in each county in terms of market equity, measured as of June of each year. As is the case for most other anomalies, the observed return effect is stronger among smaller firms, but it is not limited to them and is also significantly present among the largest and economically most important firms in European equity markets. We do not find that any of the sub-samples has a significant reversal for longer holding periods.

To conclude this chapter, we finally test whether the abnormal returns are just a compensation of risk. Table 3.4 shows estimates based on the CAPM, the three-factor model and the Carhart four-factor model regressions over the full sample period. ${ }^{6}$ Panel A of Table 3.4 shows the CAPM results; we find economically substantial and statistically significant alpha estimates in our European sample. Once again, the return premium among firms with high CO is measurable during the first year after portfolio formation, but no reversal appears in the long term.

Controlling additionally for firm size and value/growth characteristics, Panel B of Table 3.4 shows results for the three-factor model (Fama and French, 1993). Interestingly, the alpha increases slightly for all holding periods compared to the CAPM alphas. From the negative loadings on the SMB and HML factors, we learn that the High-Low portfolio is nested within large stocks with growth characteristics.

\footnotetext{
6 For simplicity we only show the high-low portfolio results.
} 
Table 3.4 Time series regressions

Panel A: $C A P M$

\begin{tabular}{ccccc}
\hline High - Low & 1 Month & $1^{\text {st }}$ Year & $2^{\text {nd }}$ Year & $3^{\text {rd }}$ Year \\
\hline \multirow{3}{*}{ Alpha } & 1.35 & & & \\
& $(9.27)$ & $(6.23)$ & 0.02 & -0.10 \\
Beta & -0.15 & -0.07 & $0.23)$ & $(-1.00)$ \\
& $(-2.56)$ & $(-1.52)$ & $(-0.11)$ & 0.03 \\
\hline
\end{tabular}

Panel B: Carhart 4 Factor

\begin{tabular}{ccccc}
\hline High - Low & 1 Month & $1^{\text {st }}$ Year & $2^{\text {nd }}$ Year & $3^{\text {rd }}$ Year \\
\hline \multirow{2}{*}{ Alpha } & 1.13 & 0.64 & 0.08 & 0.01 \\
& $(10.59)$ & $(7.23)$ & $(0.89)$ & $(0.08)$ \\
Beta & -0.06 & -0.02 & -0.04 & -0.03 \\
& $(-1.70)$ & $(-1.14)$ & $(-1.14)$ & $(-1.02)$ \\
SMB & 0.00 & -0.11 & -0.18 & -0.21 \\
& $(0.02)$ & $(-3.28)$ & $(-5.43)$ & $(-5.90)$ \\
HML & -0.12 & -0.16 & -0.26 & -0.15 \\
& $(-1.44)$ & $(-3.40)$ & $(-6.37)$ & $(-4.11)$ \\
WML & 0.32 & 0.22 & 0.04 & -0.07 \\
& $(12.62)$ & $(11.42)$ & $(1.32)$ & $(-3.87)$ \\
\hline
\end{tabular}

This table presents results from time-series regressions to explain the return premiums on the High Low CO strategy. High - Low buys firms with a CO measure within the top $20 \%$ of all firms and sells firms with a CO measure in the bottom $20 \%$. The table shows the average monthly (first column) and yearly premiums in percent, the alpha estimates, and the factor sensitives depending on the CAPM (Panel A) and the Carhart four-factor model (Panel B). The t-statistic is given in parentheses.

Panel B of Table 3.4 shows results for the four-factor model (Carhart, 1997) where we additionally add the momentum factor to the time-series regression. As a result of the high correlation between the $\mathrm{CO}$ measure and the momentum factor the alphas in the four-factor model diminish within the first year. ${ }^{7}$ However, we still find statistically and economically significant returns in up to twelve months holding periods. While in the U.S. the four-factor alphas shrink down to about a half compared to the three-factor ones, in our European sample

\footnotetext{
7 We have also redone the calculations with the three-factor model. As results stay very similar for clarity we only present results for the CAPM and the four-factor model here.
} 


\section{Chapter 3 Continuing Overreaction: European Evidence}

the alpha reduces only 24 bps from 0.88 percent per month to 0.64 percent with a strong tstatistic of 7.23 .

All in all, the results in this section strongly support Hypothesis 1. Similar to the remarkable findings of Byun et al. (2016) on the U.S. stock market, we observe a powerful positive relation between the $\mathrm{CO}$ measure and subsequent stock returns on the European stock market as well.

\subsection{Return Effects of High and Low CO Measures with Controls}

Portfolio sorts represent a very useful approach for investigating how average returns vary with different levels of $\mathrm{CO}$ measures. However, the portfolio-level analysis suffers from the lack of lost individual stock information through aggregation. Furthermore, showing that a positive return premium exists does not rule out the possibility that the identified return effect is just a manifestation of already known determinants of the cross-section of average stock returns.

To test Hypothesis 2, we therefore examine the return effects at the individual firm level using Fama and MacBeth (1973) methodology, in this section. They provide a test setting that easily allows for multiple control variables. To address this issue, we estimate a monthly firm level cross-sectional regression of the firm's future return on common firm characteristics that all predate the dependent variable.

In particular, the future return of firm $i$ in month $t$ is regressed on two binary indicator variables, denoted High and Low, in conjunction with common controls that are all available before the month in which the return measurement begins:

$r_{i, t}=a_{0, t}+a_{1, t} \mathrm{High}_{i, t}+a_{2, t} \mathrm{Low}_{i, t}+a_{3, t} \ln \left(\mathrm{SZ}_{i, t}\right)+a_{4, t} \mathrm{BM}_{i, t}+a_{5, t} \mathrm{OP}_{i, t}+a_{6, t} \mathrm{INV}_{i, t}+$

Country Dummies Dut, $_{i, t}$. 
To correct for the holding period overlap in the statistical inference (Jegadeesh and Titman, 1993) we apply Newey and West (1987) adjusted t statistics in all subsequent regressions.

The high (low) CO indicator is equal to one if the firm's continuing overreaction measure is in the top (bottom) 20 percent of all CO measures, and zero otherwise. Taking into account the most recent developments in asset pricing, the set of common firm characteristics includes firm size, book-to-market, momentum, operating profitability, and investment, that all serve as common control variables in the later cross-sectional return analyses (Fama and French, 2015). All explanatory variables are updated each June, except for momentum, which is updated monthly. Furthermore, to control for possible country effects, we include country dummies in all our regressions. Thus, the average coefficient estimate measures the withincountry effects, that is, the variables' return-predictive ability in a typical country of the sample.

Table 3.5 shows average coefficient estimates from the outlined firm-level cross-sectional regressions of overlapping yearly returns without controls to assess the high-low return behavior. The last row of each panel reports the difference between firms with high and low measures of continuing overreaction.

Table 3.5 Cross-sectional regressions

Panel A: Without Controls

\begin{tabular}{ccccc}
\hline & 1 Month & $1^{\text {st }}$ Year & $2^{\text {nd }}$ Year & $3^{\text {rd }}$ Year \\
\hline \multirow{2}{*}{ High CO } & 0.67 & 4.97 & -0.34 & -1.18 \\
& $(6.51)$ & $(4.39)$ & $(-0.37)$ & $(-1.37)$ \\
Low CO & -0.53 & -4.4 & -0.25 & -0.12 \\
& $(-6.62)$ & $(-5.59)$ & $(-0.31)$ & $(-0.18)$ \\
$\mathrm{R}^{2}$ & 0.03 & 0.04 & & 0.03 \\
High-Low & 1.21 & 9.37 & -0.09 & 0.03 \\
& $(7.80)$ & $(5.83)$ & $(-0.06)$ & -1.06 \\
& & & & $(-0.74)$ \\
\hline
\end{tabular}


Chapter 3 Continuing Overreaction: European Evidence

Panel B: With Common Controls

\begin{tabular}{ccccc}
\hline & 1 Month & $1^{\text {st }}$ Year & $2^{\text {nd }}$ Year & $3^{\text {rd }}$ Year \\
\hline \multirow{3}{*}{ High CO } & 0.15 & 2.6 & 0.57 & -0.38 \\
& $(2.67)$ & $(3.97)$ & $(0.99)$ & $(-0.96)$ \\
Low CO & -0.17 & -2.59 & -0.66 & -0.34 \\
& $(-2.69)$ & $(-4.67)$ & $(-1.12)$ & $(-0.66)$ \\
SZ & 0.06 & 0.02 & 0.16 & 0.16 \\
& $(2.09)$ & $(0.04)$ & $(0.40)$ & $(0.40)$ \\
BM & 0.28 & 3.41 & 3.35 & 2.89 \\
& $(2.83)$ & $(1.97)$ & $(1.93)$ & $(1.91)$ \\
OP & 0.1 & 1.68 & 1.69 & 1.6 \\
& $(3.90)$ & $(4.14)$ & $(3.88)$ & $(4.02)$ \\
INV & -0.38 & -3.07 & -2.77 & -1.85 \\
& $(-5.50)$ & $(-2.41)$ & $(-2.56)$ & $(-2.03)$ \\
MOM & 1.15 & 5.18 & -2.48 & -1.45 \\
& $(3.50)$ & $(1.68)$ & $(-1.01)$ & $(-0.65)$ \\
& & & & \\
$\mathrm{R}^{2}$ & 0.05 & 0.06 & 0.05 & 0.05 \\
High-Low & & & & -0.04 \\
& 0.33 & 5.19 & 1.23 & $(-0.06)$ \\
\hline
\end{tabular}

This table presents average coefficient estimates and associated Newey-West adjusted $t$-statistics (in parentheses) from monthly firm-level cross-sectional regressions. The dependent variable is the firm's future one month, first-year, second-year or third-year return after the $\mathrm{CO}$ calculation. High (Low) CO is a binary indicator variable that takes the value of one if a firm's CO measure is in the top (bottom) $20 \%$ of all firms and zero otherwise. The independent variables are firm size (SZ), bookto-market (BM), operating profitability (OP), investment (INV), and momentum (MOM). All regressions include country dummies. In the regressions, SZ and BM are measured in natural logs. $\mathrm{R}^{2}$ is adjusted for degrees of freedom. The last row provides the average return premium in percent based on the difference between the high and low coefficient estimates. Panel A reports results for the high and low coefficient estimates without controls. Panel B contains additional results for the full set of independent controls.

As expected, we find an economically strong and statistically significant premium in the first year of 9.37 , which is equally driven by the high $\mathrm{CO}$ indicator (4.97\%) and a negative low CO indicator $(-4.40 \%)$. The high-low premium is only significant in the first year after portfolio formation and becomes insignificant thereafter. 
Panel B of Table 3.5 includes the common controls as a further robustness test. The premium shrinks less than 1 percent to $8.52 \%$ for a one year holding period after portfolio formation and is still strongly significant (t-statistic 5.49). While size and book-to-market are insignificant, operating profitability loads positive and the investment factor significantly negative on the return premium.

To finally conclude whether momentum drives out the return premium of the continuing overreaction measure we include a momentum factor to the regression in Panel B of Table 3.5. While the momentum factor leads towards significance in the first year (t-statistic 1.68), it turns negative in the second year. The CO premium stays significant positive at 5.19 for the first year and still becomes insignificant thereafter.

In summary, the results in this section strongly support our Hypothesis 2. Similar to the results of prior U.S. studies, we observe an economically strong and statistically significant CO premium, that could not be explained by established cross-sectional determinates. Interestingly, even if we add a momentum factor, the $\mathrm{CO}$ premium stays significant.

\subsection{CO measures within different business conditions}

In this section, we test Hypothesis 3 that the return premium between firms with high measures of $\mathrm{CO}$ and firms with low $\mathrm{CO}$ is also present within different business conditions. It is well established that momentum profits vary within different business conditions. Chordia and Shivakumar (2002) were among the first to show that momentum performs well during expanding periods while the momentum premium is smaller within recessive periods, based on the NBER recession indicator. Further studies expand these findings with various measures of optimistic/expanding economy states versus contracting/pessimistic economy states (Jegadeesh and Titman, 2011). Hereinafter we examine whether the novel continuing overreaction measure conforms to the same return pattern as with a standard momentum approach. To address this question, we estimate monthly firm-level cross-sectional regressions based on Equation (3) for two different specifications, i.e., negative versus 


\section{Chapter 3 Continuing Overreaction: European Evidence}

positive specifications that depend on the underlying state of the economy. We use six different proxies to measure the positive/negative economic states. Namely: market volatility, market states, investor sentiment, market liquidity, default spread, and the NBER recession indicator. While market volatility as well as market states are based on European data, due to missing cross-country proxies, the remaining four measures are based on U.S. data. Baker, Wurgler and Yuan (2012) demonstrate that sentiment around the globe is predominantly driven by the U.S. sentiment and that this can therefore serve as a proxy for European sentiment as well. Moreover, the USA as the world's largest and most important equity market take up a leading role for international markets as documented by Rapach et al. (2013).

The six different proxies to measure the state of the economy are defined in the following way. Following Baker and Wurgler (2006), market volatility is the annual standard deviation of the value-weighted European market portfolio returns over the prior 12 months, skipping the most recent month. Market state is calculated using the cumulative return on the valueweighted European market portfolio over the 36 months ahead of the calculation point of the continuing overreaction measure (Cooper et al., 2004). We use the well-known Baker and Wurgler (2006) sentiment index, that uses monthly U.S. data, to capture investor sentiment. Market liquidity is measured using the noise index of $\mathrm{Hu}$ et al. (2013) that uses the aggregate noise in the prices of U.S. Treasury bonds, thus the deviation between market and modelimplied yields. We use the level of noise in the U.S. Treasury bond market as a proxy for market-wide liquidity due to the fact that this market is one of the most active and liquid markets in the world and one with the highest credit quality. Default spread is the monthly difference between a 10-year U.S. corporate bond index and 10-year U.S. Treasury bonds, as applied by Fama and French (1993). To separate crisis from non-crisis periods over the sample period, we use the NBER recession indicator for the USA. We calculate the median of market volatility, investor sentiment, market liquidity and default spread to separate between optimistic and pessimistic values for those measures, while positive (negative) 36month returns of the market indicate up (down) market states. 
Figure 3.1 illustrates the average return premiums related with continuing overreaction and a standard momentum approach; the last bars provide the difference between the $\mathrm{CO}$ and the momentum measure. The black bars illustrate pessimistic (contracting) business conditions while the clear bars display the optimistic (expanding) business conditions, as calculated by the six proxies for the state of the economy (Panel A to F). The premiums are the results from the differences between the high and low (long and short) coefficient estimates from the outlined firm-level cross-sectional regression setting. As before, we include common controls and country dummies in every single regression.

Notwithstanding the economic state proxy, both approaches gain significantly positive return premiums during optimistic periods. Across all proxies, the average $\mathrm{CO}$ profit amounts to $9.40 \%$ per year while a standard momentum approach gains $11.44 \%$ per year, as a consequence, the difference between the $\mathrm{CO}$ and momentum approach during positive business conditions is negative (-2.04\% per annum). The strong momentum premium during positive periods, as already documented by previous literature, leads to the observed return pattern and the superiority of the momentum strategy here. Chordia and Shivakumar (2002) find a significant positive return premium only during expanding periods, as well as Antoniou et al. (2013) who show that momentum profits are high during up markets and insignificant low in down markets, following the approach of Baker and Wurgler (2006) for sentiment calculations.

As a natural consequence, regardless of the applied economic state proxy, the average return premium during negative periods is significantly stronger among the novel continuing overreaction measure. The average CO premium amounts to $6.78 \%$ per annum while the momentum premium gains only $3.58 \%$, which leads to a positive difference between the two approaches of $3.20 \%$ per annum. Especially worth mentioning is the superiority of the CO measure regarding the proxies for crisis/non-crisis (NBER recession indicator) and up/down 


\section{Chapter 3 Continuing Overreaction: European Evidence}

Figure 3.1 Premiums conditional upon business conditions

Panel A: Market volatility

- High Vola $\square$ Low Vola

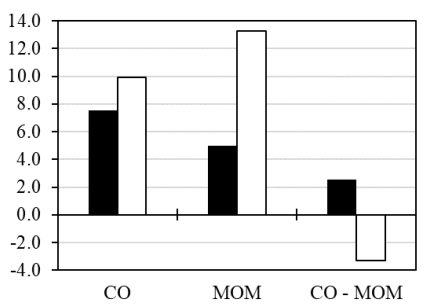

Panel C: Investor sentiment

- Low Sentiment $\square$ High Sentiment

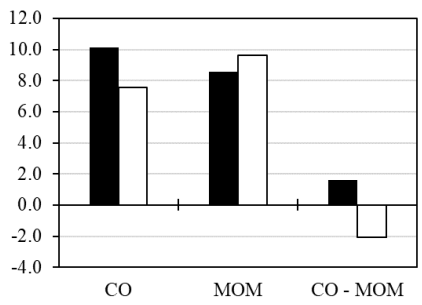

Panel E: Default spread

- High Spread aLow Spread

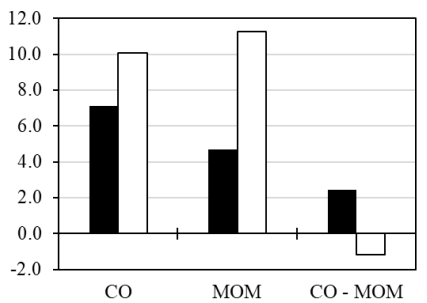

Panel B: Market states

-Down Markets $\square$ Up Markets

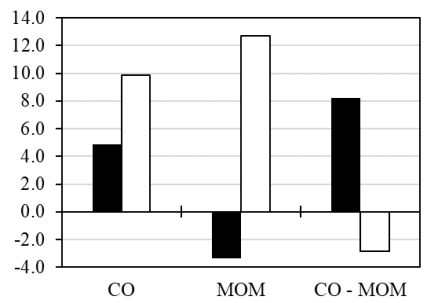

Panel D: Market liquidity

- Illiquid Markets $\quad$ Liquid Markets

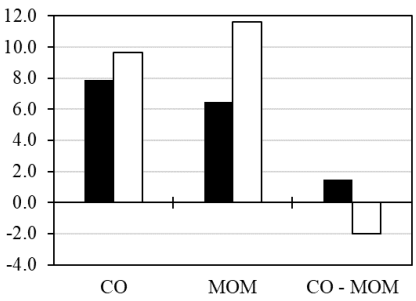

Panel F: NBER recession indicator

- Crisis aNon-Crisis

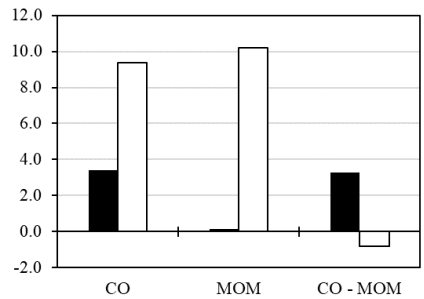

This figure illustrates the average return premiums associated with the continuing overreaction measure $(\mathrm{CO})$, a standard momentum strategy $(\mathrm{MOM})$ and the difference of both strategies $(\mathrm{CO}-$ $\mathrm{MOM}$ ) in percent per year during contracting/pessimistic business conditions (black bars) and expanding/optimistic business conditions (clear bars), as measured by six different economic state proxies (Panels A to F). 
markets. During pessimistic periods the momentum premium is near zero (crisis) or even strongly negative (down markets), while the $\mathrm{CO}$ measure gains significantly positive return premiums irrespective of the applied economic state.

In summary, on the one hand, these empirical results corroborate the findings by prior literature that the momentum premium is particularly strong during expanding/optimistic periods and very weak during contracting/pessimistic periods. On the other hand, these results clearly point out the superiority of the $\mathrm{CO}$ measure over a one year holding period in comparison to a standard momentum approach, displayed in the continuity especially during contracting/pessimistic periods.

\subsection{Conclusion}

In this paper, we study the U.S. findings of Byun et al. (2016) that a continuing overreaction measure can predict future stock returns in the broad cross-section of European firms drawn from 15 developed equity markets over the sample period from 1990 to 2018 . The measure is calculated by taking the weighted signed volume as well as past returns into account. We provide strongly supportive out-of-sample evidence on the previous findings on the U.S. stock market.

As in the United States we find a significantly positive relation between firms' continuing overreaction measure and the subsequent stock return. The outperformance of firms with high measures of continuing overreaction over low $\mathrm{CO}$ measures is not captured by established cross-sectional return determinants. The observed premium is robust to common controls based on firm size, book-to-market and momentum as well as to novel controls like profitability and investment. In addition, the premium is also present within different business conditions, we use market volatility, market states, investor sentiment, market liquidity, default spread, and the NBER recession indicator. In depth, the novel CO measure earns a significantly positive return premium over a holding period of one year that does not suffer from reversal as a standard momentum approach does in the subsequent years. 


\section{Chapter 3 Continuing Overreaction: European Evidence}

Companies with high CO measures gain abnormal returns over an observed holding period of up to three years.

Given the similarity between our European findings and the prior U.S. evidence, it is unlikely that the superior predictive power of $\mathrm{CO}$ measure is sample-specific. Indeed, our results suggest that the continuing overreaction measure is a superior applicable measure even in Europe. 


\title{
Chapter 4
}

\section{Overnight Returns: An International Sentiment Measure}

This research project is joint work with Ulrich Wessels. The paper has been published as: Florian Weißofner and Ulrich Wessels (2019), Overnight Returns: An International Sentiment Measure, Journal of Behavioral Finance, forthcoming.

\begin{abstract}
The suitability of overnight returns as a firm-specific investor sentiment measure, previously found in the US, is similarly present in international equity markets. This delivers a completely novel approach to measure investor sentiment at the firm level. For applicability reasons overnight returns have to fulfill three characteristics that would be expected of a sentiment measure. First, overnight returns persist in the short-run, second, this persistence is stronger among harder-to-value firms, and third, stocks with high overnight returns underperform in the long-run. Implementing this novel sentiment measure on a common anomaly, we find explanatory power even beyond a market-wide sentiment measure.
\end{abstract}

Keywords Investor sentiment; Overnight returns; International markets; Asset pricing; Behavioral finance 


\section{Chapter 4 Overnight Returns: An International Sentiment Measure}

\subsection{Introduction}

It is well established that sentiment plays a substantial role in stock markets all around the globe. A broad set of literature focuses on this topic and mainly concentrate on market-wide investor sentiment (Brown and Cliff, 2004; Baker and Wurgler, 2006; Stambaugh et al., 2012). However, international sentiment literature is scarce and no established sentiment measure for international stock markets is available so far (Baker et al., 2012). In a recent study on the U.S. stock market, Aboody et al. (2018) find strong evidence that overnight returns function as a measure of firm-specific investor sentiment. In particular, they document that overnight returns possess characteristics that would be expected for a sentiment measure at the firm level and present affirmative results for the price reaction to earnings announcements.

In their early theoretical work, Shleifer and Summers (1990) postulate that the trading behavior of retail investors, typically characterized as uninformed traders, is mostly affected by sentiment which makes them trade at prices not justified by news or fundamentals. Typically, sentiment-driven retail investors tend to act as a herd - trading the same stocks at the same time in the same direction - which causes price pressure and risk that may deter institutional investors from trading against them as they are likely to be risk averse. As a result, the price impact of retail investors trading is quite substantial and can cause stock prices to deviate from their underlying fundamental values. ${ }^{1}$ Using a unique dataset of retail investor's trades at a major U.S. discount broker, Kumar and Lee (2006) confirm these predictions. Specifically, they show that retail investor's sentiment has significant impact on stock prices as individual investors trading behavior is systematically correlated. ${ }^{2}$ The observed effects of sentiment-driven retail trading are particularly pronounced for stocks that

1 For further theoretical work, see De Long et al. (1990, 1991), Lee et al. (1991), Shleifer and Vishny (1997), or Barberis et al. (2005).

2 There are earlier studies which examine the correlated trading behavior of individual investors without linking the results to expected stock returns. For example, Jackson (2003) observes systematic trading patterns among retail investors in Australia. Using a Chinese data set, Feng and Seasholes (2004) document a strong correlation among the trading activities of investors that live within a certain geographic region. 
are more difficult to value and are more costly to arbitrage - two factors that hinder arbitrage trading activities by institutional investors. ${ }^{3}$

Based on the premise that retail investors face the problem that they must select from thousands of stocks when they want to buy (see Odean, 1999), Barber and Odean (2008) provide evidence that individual investors limit this search problem by focusing on stocks that recently attracted their attention. In particular, the researchers show that individual investors are net buyers on the subsequent trading day following attention-triggering events. Motivated by these observations, Berkman et al. (2012) demonstrate that the herding behavior following high-attention days creates price pressure especially at the open of the next trading day. This is due to the fact, that retail investors tend to place their orders overnight, whereas institutional investors concentrate their trading activities on the opening hours of stock exchanges because of lower trading costs and a reduced risk trading against the irrational herd of individual investors. ${ }^{4}$ Bolstered by earlier theoretical and empirical evidence that retail investors are most affected by sentiment, Berkman et al. (2012) conclude that overnight returns can serve as a measure for firm-specific sentiment.

The findings of Aboody et al. (2018) that overnight returns function as a measure of sentiment are interesting especially for international stock markets for three reasons. First, overall there is no ubiquitous sentiment measure available at the firm level, where most of the literature focuses on market-wide sentiment. ${ }^{5}$ In their seminal work, Aboody et al. (2018) provide evidence that overnight returns proxy for firm-specific investor sentiment on the U.S. equity market. Second, literature that focuses on international stock markets has to use U.S. sentiment measures as proxies for international sentiment (Walkshäusl, 2016). ${ }^{6}$ This is due

${ }^{3}$ For further evidence on the price impact of retail investors herding behavior see Hvidkjaer (2008), Kaniel et al. (2008), Barber et al. (2009b) or Berkman et al. (2012).

4 The recent evidence of Lou et al. (2018) confirms these observations.

5 See, e.g., Baker and Wurgler (2006), Arif and Lee (2014), Gao and Süss (2015), Huang et al. (2015), and Stambaugh et al. (2012).

${ }^{6}$ Eun and Lee (2010) argue that markets around the globe have become more integrated and Rapach et al. (2013) show that the USA plays a leading role for international markets. 
to the lack of a universally valid sentiment measure for international markets and based on the findings of Baker et al. (2012) that international investor sentiment is transferable and partially driven by US sentiment. ${ }^{7}$ Third, compared to the well-known and most applied sentiment measure of Baker and Wurgler (2006), the method proposed by Aboody et al. (2018) does not require special datatypes. For instance, Baker and Wurgler (2006) use the exclusive datasets for IPOs from Jay Ritter's website, which delivers data primarily for the U.S. market.

A measure to directly gauge investor sentiment on the individual firm-level would have a wide range of potential applications not just in terms of academic research but also for practioners. However, and in the sense of Lo and MacKinlay (1990), any finding in empirical research could be the result of data snooping and therefore be sample-specific. In consequence, it is questionable whether overnight returns really function as a proxy for investor sentiment out-of-sample. Since international stock markets provide an ideal testsetting to challenge the results of Aboody et al. (2018), we examine the suitability of overnight returns as a measure of firm-specific sentiment in the broad cross-section of international, non-American firms. Observing similar results to the recent U.S. evidence in Aboody et al. (2018) would strengthen their findings and the importance of overnight returns in a behavioral context. That may ultimately lead to a better understanding of overnight returns around the globe and extends the application scope for a firm-specific sentiment measure to international equity markets.

In addition to the extensive out-of-sample evidence, we contribute to the literature by analyzing the suitability of overnight returns as a firm-specific investor sentiment measure in a cross-sectional test setting which has two advantages compared to the time-series test setting applied by Aboody et al. (2018). First, we can directly examine the effect of overnight returns at the firm-level leaving out possible portfolio effects, which could bias the results.

\footnotetext{
7 As a direct measure is not available so far, Schmeling (2009) use consumer confidence as a proxy for the investor sentiment on international markets.
} 
Second, conventional time-series test settings to calculate abnormal returns are based on close-to-close returns, whereas we examine overnight returns. However, a cross-sectional test setting allows us to easily control for various return determinants typically used in asset pricing literature as the respective characteristics can directly be used as explanatory variables. Finding evidence would be a substantial contribution for international sentiment literature, as overnight returns could be used as a direct sentiment measure on any examined equity market. Therefore, sentiment for international markets could be determined at the firm-level and no proxies would be necessary.

Specifically, derived from Aboody et al. (2018) we test the following three hypotheses outof-sample in international stock markets. Finding supporting evidence for all of the three hypotheses is necessary to confirm the suitability of overnight returns as a firm-specific sentiment measure.

The first hypothesis addresses the short-run persistence of overnight returns. According to Barber et al. (2009a), the investment behavior of retail investors is strongly affected by sentiment. They conclude that a disparity in orders of retail investors remains persistent over subsequent weeks. Taking into account that Berkman et al. (2012) show that retail investors tend to place orders outside the opening hours of stock exchanges, overnight returns should remain similarly persistent over several weeks.

Hypothesis 1: Firms with high overnight returns yield significantly positive risk-adjusted returns in the short-run.

Our second hypothesis is motivated by the findings of Baker and Wurgler (2006). They show that market-wide sentiment has a greater impact on firms that are objectively harder-to-value. Further literature also shows that sentiment affects the returns of firms that are harder to value more, than firms that are easier to value. ${ }^{8}$

8 See e.g., Berkman et al. (2009), Hirbar and McInnis (2012), and Seybert and Yang (2012). 
Specifically, in line with Aboody et al. (2018) we test the short run persistence for five harderto-value measures, namely size, book-to-market ratio, operating profitability, volatility and age. For the validity of the assumption, the overnight return persistence should be stronger among firms that are objectively harder-to-value.

Hypothesis 2: The short-run overnight return persistence is significantly higher for harderto-value firms.

The third hypothesis addresses the long-term underperformance of stocks with high demand from retail investors in the short-run. This assumption is based on the findings of Hvidkjaer (2008) and Barber et al. (2009a), who show that stocks with high short-term demand from retail investors underperform those stocks with relatively low short-term demand. This temporary mispricing is a characteristic what is expected of a sentiment measure. Even Baker and Wurgler (2006) argue that stocks with more attention from optimistic traders earn lower returns over the subsequent 12 months. Therefore, the returns in the long-run should be smaller among the firms with high overnight returns.

Hypothesis 3: Stocks with high overnight returns yields significantly smaller risk-adjusted returns in the long-run.

Our results are easily summarized. Similar to the United States, overnight returns are suitable as an international measure for firm-specific investor sentiment. First, we find a significant and positive overnight return persistence for about four weeks or longer after portfolio formation that cannot be explained by established return predictors of the cross-section. Second, the overnight return persistence is considerable larger among firms that are harder to value, even though we control for common risk factors. Thus, the effect is stronger for firms that are smaller, have a high book-to-market ratio, a low profitability, a high volatility or have a younger age. Third, stocks with high overnight returns in the short run obtain negative total returns in the long run and vice versa. 
Taken together, our out-of-sample analysis strongly supports the findings in Aboody et al. (2018). Hence, the overnight return effect and consequently its applicability as a firm-specific sentiment measure seems to be a phenomenon across stock markets.

The remainder of the paper is organized as follows. Section 2 describes the data and variables used in this study. Section 3 examines the short-run persistence of overnight returns. Section 4 investigates whether the observed return behavior is stronger among harder-to-value firms. Section 5 studies the long-term behavior of stocks with strong overnight returns in the short run. Section 6 presents application results and Section 7 concludes the paper.

\subsection{Data and Variables}

We study an international country sample that consists of firms from 20 developed non-U.S. equity markets: Australia, Austria, Belgium, Denmark, Finland, France, Germany, Hong Kong, Ireland, Italy, Japan, Netherlands, New Zealand, Norway, Portugal, Singapore, Spain, Sweden, Switzerland and the United Kingdom. The sample selection mirrors the countries included in the famous Europe, Australia and the Far East (EAFE) stock market benchmark form MSCI that measures stock market performance outside of North America. We collect daily closing and opening prices on common stocks from Datastream and firm-level accounting information (e.g., book equity) from Worldscope. We calculate the daily closeto-close (total) return, $r_{\text {close-to-close }, t}^{i}$, using standard total return prices. The intraday return, $r_{\text {intraday, }}^{i}$, is the return between the opening and closing of the same day $t$. Given that Datastream provides total return prices only for the close, we calculate intraday returns with adjusted opening and closing prices in line with the methodology proposed by Lou et al. (2018). Therefore, we assume that dividend adjustments that could move share prices occur overnight. ${ }^{9}$ The overnight return is then calculated as the deviation between close-to-close and intraday return.

\footnotetext{
9 Results are similar when we use local currencies.
} 


$$
r_{\text {intraday }, t}^{i}=\frac{P_{t}^{i}}{P O_{t}^{i}}-1,
$$

where $P_{t}^{i}$ is the closing price for the shares of firm i on day t, and $P O_{t}^{i}$ is the opening price for the shares on day $\mathrm{t}$.

$$
r_{\text {close-to-close }, t}^{i}=\frac{R I_{t}^{i}}{R I_{t-1}^{i}}-1
$$

where $R I_{t}^{i}$ is the total return closing price for the shares of firm i on day t, and $R I_{t-1}^{i}$ is the total return closing price for the shares on day $\mathrm{t}-1$.

$$
r_{\text {overnight }, t}^{i}=\frac{1+r_{\text {close-to-close }, t}^{i}}{1+r_{\text {intraday }, t}^{i}}-1
$$

Following Lou et al. (2018), we then calculate the weekly overnight returns, taking the compounded daily overnight return starting on Wednesday of week w - 1 and ending on Tuesday of week w. ${ }^{10}$ The weekly close-to-close return is calculated by the same method.

To ensure that accounting information is known before the returns are calculated, we match the latest accounting information for the fiscal year ending in the previous calendar year with stock returns from the first week in July ( week 27$)$ of the current year to the end of June ( week 26) of the subsequent year throughout the paper. All data are denominated in U.S. dollars. ${ }^{11}$ To ensure that our results are not driven by tiny or illiquid stocks, we follow Ang, Hodrick, Xing, and Zhang (2009) and exclude very small firms by eliminating the 5 per cent

\footnotetext{
${ }^{10}$ Beginning on Wednesday is consistent with Lehmann (1990) and Barber et al. (2009a).

${ }^{11}$ We have also redone all calculations with local currencies and gain very similar results.
} 
of firms with the lowest market equity in each country. Furthermore, as in Fama and French (1992) firm-year observations with negative book equity are excluded from the sample. Due to the fact that most of the countries have reported opening prices since 1992, our sample period starts in the first week of July in 1992 and ends in the last week of June 2017.

Panel A of Table 4.1 reports a summary statistic for the countries included in the international sample. On average our sample includes 7918 firms, where the largest portion falls on the countries Japan and the United Kingdom.

The variables used in this study are defined as follows. Beta (BETA) is estimated relative to all stocks using 5 years (60 months) of past returns. A firm's size (SZ) is its stock price multiplied by the number of shares outstanding, calculated as of the end of every month in million U.S. dollars. Book-to-market (BM) is the ratio of book equity to market equity at the fiscal year-end. Momentum (MOM) is the cumulative prior six-month stock return, skipping the most recent month (Jegadeesh and Titman, 1993). Following Fama and French (2015), investment (INV) is the annual change in total assets divided by lagged total assets. Operating profitability (OP) is revenues minus cost of goods sold and interest expense, all divided by book equity. Age (AGE) is the number of years since a company was founded. In line with Aboody et al. (2018) volatility (VOL) is calculated as the standard deviation of monthly stock returns for the prior twelve-month stock return, skipping the most recent month. 
Chapter 4 Overnight Returns: An International Sentiment Measure

Table 4.1 Summary Statistics

Panel A: Sample Countries

\begin{tabular}{lclc}
\hline Country & Firms & Country & Firms \\
\hline Australia & 720 & Japan & 2804 \\
Austria & 38 & Netherlands & 121 \\
Belgium & 86 & New Zealand & 72 \\
Denmark & 93 & Norway & 129 \\
Finland & 111 & Portugal & 38 \\
France & 460 & Singapore & 307 \\
Germany & 464 & Spain & 113 \\
Hong Kong & 621 & Sweden & 254 \\
Ireland & 23 & Switzerland & 176 \\
Italy & 205 & United Kingdom & 1083 \\
\hline
\end{tabular}

Panel B: Variables

\begin{tabular}{lcccc}
\hline Variable & Mean & 25th & Median & 75th \\
\hline & & & & \\
BETA & 0.92 & 0.51 & 0.86 & 1.26 \\
SZ & 1273.32 & 55.03 & 171.81 & 670.42 \\
BM & 0.98 & 0.43 & 0.75 & 1.24 \\
MOM & 0.06 & -0.14 & 0.02 & 0.20 \\
OP & 0.72 & 0.23 & 0.50 & 0.90 \\
INV & 0.16 & -0.05 & 0.05 & 0.17 \\
AGE & 38.61 & 15.96 & 33.99 & 58.61 \\
VOL & 0.38 & 0.23 & 0.32 & 0.47 \\
\hline
\end{tabular}

This table shows summary statistics for the countries included in the international (EAFE) sample and the variables used in this study. Panel A reports the average number of firms in each country over the sample period from July 1992 to June 2017. For the most part of the sample data is available since 1992 namely, Australia, Austria, Belgium, Denmark, France, Germany, Italy, Japan, Netherlands, Portugal, Singapore, Spain, Switzerland, United Kingdom. For the rest of the sample data history for opening prices starts later, specifically Finland (2001/03), Hong Kong (1994/06), Ireland (1999/01), New Zealand (1996/02), Norway (1995/12), and Sweden (2001/06). Panel B reports the mean, 25th percentile, median, and 75 th percentile of the variables. Beta (BETA) is estimated relative to all stocks using 60 months of past returns. Size (SZ) is market equity (stock price multiplied by the number of shares outstanding) at the end of the previous month. Book-to-market (BM) is the ratio of book equity to market equity for the fiscal year ending in the previous calendar year. Momentum (MOM) is the cumulative prior six-month stock return, skipping the most recent month. Operating profitability $(\mathrm{OP})$ is revenues minus cost of goods sold and interest expense, all divided by book equity. Investment (INV) is the annual change in total assets divided by total assets. Age (AGE) is the number of years since the firms' foundation (calculated as of the end of each month). Volatility (VOL) is the standard deviation of prior twelve-month stock return, skipping the most recent month. 
Panel B of Table 4.1 presents a summary statistic for variables used in this study. Focusing on the key variables of interest that moreover serve as our hard-to-value measures, we observe that a typical firm in our sample has an average size of $\$ 1.273$ million, an average book-to-market ratio of 0.98 and a mean operating profitability of 0.72 . The age of firms exhibits a mean (median) of 38.61 (33.99) years and the mean (median) volatility is $38 \%$ (32\%) among the whole sample.

\subsection{Short-Term Persistence in Overnight Returns}

In this section, we test Hypothesis 1 that firms with high overnight returns yield significantly positive overnight returns in the short run. We first present the baseline results for our international sample and further examine the robustness of our main findings with respect to common control variables and different subsamples.

\section{Baseline results}

To obtain a first impression of the persistence of overnight returns, we begin our analysis at the portfolio level. In particular, each Wednesday, we form quintile portfolios by sorting stocks based on their overnight return of week w. We then calculate the subsequent average weekly overnight returns for the following weeks $w+1$ up to week $w+4$.

Table 4.2 presents average weekly returns for quintile portfolios sorted on overnight returns. Panel A of Table 4.2 shows associated overnight returns for subsequent weeks. While the lowest quintile displays $-0.91 \%$ for week $\mathrm{w}+1$ the quintile with the highest past overnight returns displays $0.95 \%$ in week $w+1$. Accordingly, this yields a highly significant positive return of $1.86 \%$ for the high minus low portfolio in week $\mathrm{w}+1$. The long-short return decreases slightly during the following weeks; however it is still strong and significant in week $w+4(1.41 \%)$. Thus, we note that a long-short strategy based on past overnight returns produces significant return differences over the following weeks. These findings are in line with the U.S. findings by Aboody et al. (2018). 
Chapter 4 Overnight Returns: An International Sentiment Measure

Table 4.2 Persistence of Weekly Overnight Returns and Related Weekly Close-to-Close Returns

Panel A: Persistence of Overnight Returns

\begin{tabular}{|c|c|c|c|c|}
\hline Quintiles & \multicolumn{4}{|c|}{ Average weekly overnight return } \\
\hline OVN Returns & Week w +1 & Week $w+2$ & Week w +3 & Week w +4 \\
\hline 1 & -0.91 & -0.79 & -0.73 & -0.69 \\
\hline 2 & -0.00 & 0.04 & 0.04 & 0.04 \\
\hline 3 & 0.20 & 0.20 & 0.20 & 0.19 \\
\hline 4 & 0.42 & 0.37 & 0.36 & 0.36 \\
\hline 5 & 0.95 & 0.79 & 0.73 & 0.72 \\
\hline$(5)-(1)$ & $\begin{array}{c}1.86 \\
(37.90)\end{array}$ & $\begin{array}{c}1.58 \\
(40.26)\end{array}$ & $\begin{array}{c}1.46 \\
(33.29)\end{array}$ & $\begin{array}{c}1.41 \\
(35.23)\end{array}$ \\
\hline
\end{tabular}

Panel B: Behavior of Related Close-to-Close Returns

\begin{tabular}{|c|c|c|c|c|}
\hline & \multicolumn{4}{|c|}{ Average weekly close-to-close return } \\
\hline OVN Returns & Week $w+1$ & Week $w+2$ & Week $w+3$ & Week w +4 \\
\hline 1 & 0.24 & 0.16 & 0.14 & 0.15 \\
\hline 2 & 0.21 & 0.19 & 0.17 & 0.19 \\
\hline 3 & 0.21 & 0.19 & 0.20 & 0.19 \\
\hline 4 & 0.21 & 0.19 & 0.20 & 0.19 \\
\hline 5 & 0.10 & 0.15 & 0.16 & 0.19 \\
\hline$(5)-(1)$ & $\begin{array}{c}-0.14 \\
(-4.19)\end{array}$ & $\begin{array}{c}-0.01 \\
(-0.37)\end{array}$ & $\begin{array}{c}0.02 \\
(0.93)\end{array}$ & $\begin{array}{c}0.04 \\
(1.24)\end{array}$ \\
\hline
\end{tabular}

This table presents average weekly overnight and close-to-close returns for week $w+1$ through $w+$ 4. The weekly overnight returns on the stock of firm i during week $w$ is the accumulated daily overnight return beginning on Wednesday of week $\mathrm{w}-1$ and ending on Tuesday of week $\mathrm{w}$. The weekly close-to-close return for week $\mathrm{w}$ is the compounded daily return over the period beginning on Wednesday of week w -1 and ending on Tuesday of week w. We rank all stocks each week in ascending order according to their overnight return that week and partition the stocks into quintiles. Panel A reports the average weekly overnight return over the subsequent 4 weeks for the stocks in each quintile. The last row provides the average spread return between firms with high and low overnight return. Panel B reports the average weekly close-to-close return. The Newey-West adjusted $\mathrm{t}$-statistic is given in parentheses. 
For a comprehensive picture, we calculate the average weekly close-to-close (total) returns for the quintile portfolios for week $w+1$ through week $w+4$ (Panel B of Table 4.2). Unlike the overnight returns, the weekly total returns are not persistent throughout the weeks. Week $\mathrm{w}+1$ displays a slightly negative return premium for the long-short strategy $(-0.14 \%)$, week $\mathrm{w}+2$ through week $w+4$ yield no significant return results. Interestingly, the insignificant long-short portfolio returns seem to be the outcome of strong returns in the lowest portfolio, compared to Panel A of Table 4.2. To sum up, overnight returns have no predictive power for short term total returns. These findings are also in line with Aboody et al. (2018) who could not find steady total returns within the U.S. equity market either.

\section{Common risk factors and robustness}

Portfolio sorts represent a very useful approach to investigate how average returns vary with different levels of overnight returns. However, as it is of particular interest whether overnight returns can be used as a sentiment measure at the firm level, we now study the overnight return persistence at the individual firm level using the Fama and MacBeth (1973) methodology, which provides a test setting that easily allows for multiple control variables.

In particular, we estimate a weekly cross-sectional regression of average weekly overnight returns in conjunction with common controls. Furthermore, we introduce a high (low) indicator variable that is equal to one if the firm's overnight return of week w falls in the top (bottom) 20 per cent of all stocks and zero otherwise. Following Fama and French (2015), the set of common control variables includes beta (BETA), firm size (SZ), book-to-market (BM), operating profitability (OP), investment (INV) and momentum (MOM). The explanatory variables are either updated at the end of each June (BETA, SZ, BM, OP, INV) or weekly (MOM) to predict weekly overnight returns. 
Panel A of Table 4.3 presents average coefficient estimates for weeks $\mathrm{w}+1$ to $\mathrm{w}+4$ within the outlined weekly firm-level cross-sectional regression to assess the persistence of the longshort premium across time. The last row provides the economic and statistical significance of the average high-low returns reporting the difference between the high and low coefficient estimates.

Table 4.3 Cross-Sectional Regressions of Weekly Overnight Returns on Overnight Return Indicators and Common Controls

Panel A: Overnight Return Persistence throughout Subsequent Weeks

\begin{tabular}{lcccc}
\hline & Week w +1 & Week w +2 & Week w+3 & Week w + 4 \\
\hline \multirow{3}{*}{ High } & & & & \\
& 0.73 & 0.58 & 0.50 & 0.52 \\
Low & $(25.74)$ & $(23.20)$ & $(22.17)$ & $(24.15)$ \\
BETA & -1.05 & -0.90 & -0.81 & -0.78 \\
& $(-26.65)$ & $(-27.00)$ & $(-23.92)$ & $(-25.05)$ \\
SZ & 0.19 & 0.20 & 0.20 & 0.20 \\
& $(10.73)$ & $(11.95)$ & $(12.12)$ & $(11.67)$ \\
BM & 0.03 & 0.03 & 0.04 & 0.04 \\
& $(3.06)$ & $(4.02)$ & $(4.29)$ & $(4.13)$ \\
OP & -0.06 & -0.07 & -0.07 & -0.08 \\
& $(-4.29)$ & $(-5.23)$ & $(-5.48)$ & $(-5.81)$ \\
INV & 0.01 & 0.00 & 0.00 & 0.00 \\
& $(1.12)$ & $(0.80)$ & $(0.75)$ & $(0.86)$ \\
MOM & 0.01 & 0.02 & 0.02 & 0.02 \\
& $(0.78)$ & $(1.39)$ & $(1.15)$ & $(1.16)$ \\
& -0.51 & -0.28 & -0.22 & -0.16 \\
$\mathrm{R}^{2}$ & $(-5.51)$ & $(-4.14)$ & $(-3.63)$ & $(-2.86)$ \\
& & & & \\
High-Low & 0.08 & 0.07 & 0.07 & 0.07 \\
& & & & \\
& 1.77 & 1.47 & 1.32 & $(33.82)$ \\
\hline
\end{tabular}


Chapter 4 Overnight Returns: An International Sentiment Measure

Panel B: Robustness of Overnight Return Persistence

\begin{tabular}{lccccc}
\hline & Earlier & Later & Europe & Asia Pacific & Japan \\
\hline \multirow{3}{*}{ High } & & & & & \\
& 0.94 & 0.54 & 1.16 & 0.65 & 0.20 \\
Low & $(26.08)$ & $(27.97)$ & $(12.52)$ & $(18.22)$ & $(15.68)$ \\
& -1.03 & -1.06 & -1.49 & -1.44 & -0.35 \\
BETA & $(-14.83)$ & $(-25.97)$ & $(-25.42)$ & $(-17.06)$ & $(-18.38)$ \\
& -0.03 & 0.13 & 0.17 & 0.17 & 0.16 \\
SZ & $(-3.19)$ & $(6.24)$ & $(12.66)$ & $(8.57)$ & $(5.06)$ \\
& -0.03 & 0.08 & 0.06 & 0.05 & 0.01 \\
BM & $(-3.19)$ & $(10.06)$ & $(5.14)$ & $(5.21)$ & $(0.52)$ \\
& -0.00 & -0.11 & 0.01 & -0.32 & 0.02 \\
OP & $(-0.10)$ & $(-9.44)$ & $(0.56)$ & $(-12.99)$ & $(1.48)$ \\
& 0.04 & -0.02 & -0.00 & -0.03 & 0.03 \\
INV & $(5.53)$ & $(-4.38)$ & $(-0.22)$ & $(-0.95)$ & $(7.26)$ \\
& -0.06 & 0.09 & 0.02 & 0.12 & -0.12 \\
MOM & $(-2.12)$ & $(7.12)$ & $(1.25)$ & $(6.02)$ & $(-3.46)$ \\
& -0.94 & -0.12 & -0.50 & -0.12 & -1.16 \\
& $(-8.90)$ & $(-1.06)$ & $(-6.17)$ & $(-0.95)$ & $(-9.00)$ \\
$\mathrm{R}^{2}$ & & & & & \\
\multirow{2}{*}{ High-Low } & 0.09 & 0.06 & 0.05 & 0.06 & 0.04 \\
& & & & & \\
& 1.97 & 1.59 & 2.65 & 2.09 & 0.54 \\
& $(21.15)$ & $(31.76)$ & $(19.71)$ & $(23.67)$ & $(23.08)$ \\
\hline
\end{tabular}

This table presents average coefficient estimates and associated Newey-West adjusted $t$-statistics (in parentheses) from weekly firm-level cross-sectional regressions. The dependent variable is the firm's future weekly overnight stock return. The overnight return indicator high (low) is equal to one if the firm's weekly overnight return is in the top (bottom) 20 per cent during the formation week w, and zero otherwise. The independent variables are beta (BETA), firm size (SZ), book-to-market (BM), operating profitability (OP), investment (INV), and momentum (MOM). All regressions include country dummies. In the regressions, $\mathrm{SZ}$ and $\mathrm{BM}$ are measured in natural logs. $\mathrm{R}^{2}$ is adjusted for degrees of freedom. The last row provides the average return premium in percent per week based on the difference between the high and low coefficient estimates. Panel A reports results for short-run persistence for week $\mathrm{w}+1$ through week $\mathrm{w}+4$. Panel B reports robustness results for week $\mathrm{w}+1$. The earlier and later half samples cover July 1992 to June 2004 and July 2004 to June 2017, respectively. Europe includes Austria, Belgium, Denmark, Finland, France, Germany, Ireland, Italy, Netherlands, Norway, Portugal, Spain, Sweden, Switzerland and the United Kingdom. Asia Pacific encompasses the remaining sample countries excluding Japan (see Table 4.1). 
Beginning with week $\mathrm{w}+1$, we find a significant positive coefficient estimate on the high indicator of 0.73 per cent per week while the low indicator is significantly negative at -1.05 per cent. This leads to a highly significant and large high-low premium of 1.77 per cent per week (t-statistic 32.51) in the first week. Similar to Panel A of Table 4.2, the returns decline constantly throughout the subsequent weeks but are still strong (1.30\%) in week 4 .

Given that we examine weekly overnight returns, our results deviate from effects observed in a standard cross-sectional regression setting. Panel A of table 4.3 shows overnight returns load positive on beta $(0.19 \%)$ as well as on size $(0.05 \%)$ in week $\mathrm{w}+1$ and stay almost unchanged throughout the weeks. The returns load significantly negative on book-to-market in every single week. Operating profitability appears to be slightly positive but us insignificant over the observed period. The estimated coefficient for investment is insignificant and close to zero for the observed period. Finally, the returns load significantly negative on momentum especially for week $w+1(-0.51 \%)$ and halve in the subsequent weeks but the premium still stays significantly negative. The negative momentum premium seems to be a consequence of bid-ask spread and price pressure that appears in the very short term (Jegadeesh and Titman, 1993). Taken together in the very short term overnight returns load positive on size and profitability while they load negative on book-to-market and momentum.

The previous findings strongly support Hypothesis 1 that overnight returns are persistent in the short-run. Nevertheless, to ensure that our results are robust, Panel B of Table 4.3 presents average coefficient estimates for week $\mathrm{w}+1$ for different sub-samples to assess the pervasiveness of overnight returns across different sample periods and different regions. ${ }^{12}$ To address how persistent the observed effect is over time we divide our sample into two sub-periods. The earlier sub-period is from the first week in July in 1992 to the last week in June in 2004, while the later sub-period is from the beginning of July in 2004 to end of June

\footnotetext{
${ }^{12}$ As the results for subsequent weeks stay almost unchanged, for clarity we only present results for week $\mathrm{w}+$ 1 here.
} 
in 2017. As shown in the last row of Panel B, the return premium of overnight returns is economically sustainable and statistically highly significant in both sub-periods. Whereas the premium is slightly stronger in the earlier (1.88\%) period, it still yields $1.54 \%$ in the more recent half of the sample period. ${ }^{13}$

The Europe subsample yields a tremendously positive premium of 2.65 per cent per month in the first week after portfolio formation. A significantly positive high indicator $(1.16 \%)$ as well as a significantly negative low indicator (-1.49\%) equally drive the premium. Following Fama and French (2012), we divide the Asia subsample in Japan and Asia Pacific (including Australia, New Zealand, Hong Kong, and Singapore). Similar to the European sample the Asia Pacific sample performs quite well with a positive premium of 2.09 per cent for the first week. As expected from momentum studies on the Japanese equity market, the premium for the Japan sub-sample is considerably weaker. ${ }^{14}$ This might be due to missing individualism as described by Chui et al. (2010). Another explanation might be that this is simply due to chance as argued by Fama and French (2012). Nevertheless, and in contrast to a standard momentum approach, overnight returns still amount to a significant and positive premium of 0.54 per cent for the first week after portfolio formation for the Japan sub-sample.

In sum, the results in this section strongly support Hypothesis 1. Similar to the prior U.S. evidence, we observe a significant persistence of overnight returns, that cannot be explained by established cross-sectional return determinants, and that is robust within different subperiods and regions.

\footnotetext{
${ }^{13}$ We have also redone the calculations for a sub-sample spanning from December 2007 till June 2009 based on the NBER recession indicator to examine how our results are affected by the global financial crisis. While the Low coefficient is more pronounced during this period, the premium is quite similar as among the full sample period.

${ }^{14}$ Asness et al. (2013) and Fama and French (2012) find no momentum premium in Japan following a standard momentum approach.
} 


\subsection{Higher Spread for HTV Firms}

Baker and Wurgler (2006) already concluded that sentiment has greater impacts on considerably harder-to-value firms. ${ }^{15}$ Therefore, we test whether the overnight return pervasiveness is even stronger for harder-to-value firms in our Hypothesis 2. Finding this would support that overnight returns can be used as an international measure for sentiment. Following Aboody et al. (2018), we use five harder-to-value characteristics, namely firm size, book-to-market, profitability, volatility, and age. ${ }^{16}$ Consistent with previous literature, firms that are small, have a high book-to-market ratio (as a proxy for growth opportunities), are less profitable, have a high stock return volatility or are young are harder to value. ${ }^{17}$

Table 4.4 Cross-Sectional Regressions of Weekly Overnight Returns and Hard-to-Value Proxies

Panel A: Cross-Sectional Regressions of Weekly Overnight Returns and HTV Proxies without Controls

\begin{tabular}{|c|c|c|c|c|c|}
\hline & SIZE & BM & OP & VOL & AGE \\
\hline OVN & $\begin{array}{c}0.13 \\
(65.11)\end{array}$ & $\begin{array}{c}0.14 \\
(38.19)\end{array}$ & $\begin{array}{c}0.14 \\
(33.26)\end{array}$ & $\begin{array}{c}0.14 \\
(43.80)\end{array}$ & $\begin{array}{c}0.13 \\
(33.93)\end{array}$ \\
\hline $\begin{array}{l}\text { OVN x } \\
\text { DHTV }\end{array}$ & 0.04 & 0.02 & 0.02 & 0.02 & 0.06 \\
\hline & $(4.28)$ & $(3.83)$ & $(6.71)$ & $(4.97)$ & (9.09) \\
\hline SZ & $\begin{array}{c}0.05 \\
(5.32)\end{array}$ & & & & \\
\hline $\mathrm{BM}$ & & $\begin{array}{c}-0.07 \\
(-9.76)\end{array}$ & & & \\
\hline OP & & & $\begin{array}{c}0.02 \\
(6.48)\end{array}$ & & \\
\hline VOL & & & & $\begin{array}{c}0.21 \\
(2.45)\end{array}$ & \\
\hline AGE & & & & & $\begin{array}{c}0.20 \\
(7.11)\end{array}$ \\
\hline $\mathrm{R}^{2}$ & 0.09 & 0.09 & 0.08 & 0.09 & 0.09 \\
\hline
\end{tabular}

${ }^{15}$ Other references: Hribar and McInnis (2012) and Seybert and Yang (2012).

${ }^{16} \mathrm{We}$ use book-to-market instead of earnings-to-price, as it is more common in literature as a measure of growth (e.g., Fama and French, 2012).

${ }^{17}$ For example Baker and Wurgler (2006), Mian and Sankaraguruswamy (2012) and Seybert and Yang (2012), also use at least one of these characteristics as a hard-to-value proxy. 
Chapter 4 Overnight Returns: An International Sentiment Measure

Panel B: Cross-Sectional Regressions of Weekly Overnight Returns and HTV Proxies with Controls

\begin{tabular}{lccccc}
\hline & SIZE & BM & OP & VOL & AGE \\
\hline OVN & & & & & \\
& 0.13 & 0.15 & 0.14 & 0.14 & 0.14 \\
OVN x & $(61.43)$ & $(36.40)$ & $(30.82)$ & $(38.66)$ & $(31.22)$ \\
DHTV & 0.06 & 0.02 & 0.02 & 0.02 & 0.07 \\
& $(4.22)$ & $(2.49)$ & $(7.35)$ & $(4.82)$ & $(10.08)$ \\
BETA & 0.17 & 0.16 & 0.16 & 0.13 & 0.16 \\
& $(9.85)$ & $(9.80)$ & $(9.83)$ & $(10.31)$ & $(9.22)$ \\
SZ & 0.04 & 0.04 & 0.04 & 0.05 & 0.03 \\
& $(4.90)$ & $(4.20)$ & $(4.29)$ & $(6.43)$ & $(3.59)$ \\
BM & -0.06 & -0.06 & -0.05 & -0.05 & -0.04 \\
& $(-4.49)$ & $(-5.02)$ & $(-4.03)$ & $(-4.29)$ & $(-2.69)$ \\
OP & 0.01 & 0.01 & 0.01 & 0.01 & 0.02 \\
& $(1.28)$ & $(1.47)$ & $(1.76)$ & $(1.38)$ & $(3.54)$ \\
INV & 0.02 & 0.02 & 0.02 & 0.02 & 0.02 \\
& $(1.16)$ & $(1.05)$ & $(1.02)$ & $(1.08)$ & $(1.45)$ \\
MOM & -0.54 & -0.55 & -0.56 & -0.58 & -0.56 \\
& $(-6.39)$ & $(-6.32)$ & $(-6.38)$ & $(-6.52)$ & $(-7.12)$ \\
VOL & & & & 0.31 & \\
AGE & & & & $(4.86)$ & \\
& & & & & 0.16 \\
$\mathrm{R}^{2}$ & & & & & $(7.30)$ \\
& & & & 0.09 & 0.09 \\
\hline
\end{tabular}

This table presents average coefficient estimates and associated Newey-West adjusted $t$-statistics (in parentheses) from weekly firm-level cross-sectional regressions. The dependent variable is the firm's overnight return in week $\mathrm{w}+1$. See Table 4.3 , for a description of the independent variables. OVN is the firm's overnight return of week w. DHTV is a dummy variable based on the corresponding harder-to-value characteristic namely size, book-to-market, operating profitability, volatility and age. For size (SIZE), operating profitability (OP) and age (AGE) the dummy (DHTV) is one if the characteristic is above $75 \%$ and zero otherwise. For book-to-market (BM) and volatility (VOL) the dummy is one if the characteristic is below $25 \%$ and zero otherwise. In the regressions, SZ and BM are measured in natural logs. $\mathrm{R}^{2}$ is adjusted for degrees of freedom. Panel A reports results for the previous overnight return $(\mathrm{OVN})$, the interaction term (OVNxDHTV) and the specific harder-tovalue characteristic. Panel B contains additional results for the full set of independent controls (see Table 4.3). 
To test how the overnight returns vary between firms with different levels of hard-to-value characteristics, we proceed as follows. We estimate cross-sectional regressions of weekly overnight returns for week $w+1$ on the overnight return of week w without control variables (Panel A of Table 4.4) and with the full set of control variables as outlined in Table 4.3 (Panel $\mathrm{B}$ of Table 4.4). To study the relation between overnight returns and the harder-to-value characteristics, we take the above mentioned harder-to-value characteristics into account. Furthermore, we employ an interaction term between overnight returns (OVN) and a dummy variable (DHTV) that equals one if a firm is objectively harder-to-value and zero otherwise. The interaction terms capture the differential overnight return effects regarding the particular hard-to-value characteristic.

For size the related dummy variable is one if a firm's size (SZ) is in the bottom quartile and zero otherwise. Dummy variables for profitability (OP) and age (AGE) are constructed accordingly and become one if the characteristic is in the bottom quartile of profitability or age respectively, and zero otherwise. The dummy variable for book-to-market (BM) and volatility (VOL) equals one if the variable is in the top quartile and zero otherwise. The interaction term (OVNxDHTV) is then the overnight return (OVN) of week w multiplied with the determined harder-to-value dummy (DHTV). Thus, the average coefficient estimate on the interaction term provides the economic difference of the overnight returns between firms with high levels of harder-to-value characteristics and the residual firms.

Based on the previous findings in the literature and the alignment of our dummy variables, we expect positive estimates on every single interaction term between overnight returns and the hard-to-value characteristic to confirm Hypothesis 2. Therefore, the overnight return persistence should be stronger among firms that are objectively harder-to-value.

Table 4.4 presents average coefficient estimates from the outlined weekly cross-sectional regressions for each of our five hard-to-value measures. For brevity, we only report results 
for week $\mathrm{w}+1 .{ }^{18} \mathrm{We}$ provide results that control only for the respective harder-to-value characteristic in Panel A of Table 4.4, and for robustness concerns, additionally control for the full set of common controls in Panel B of Table 4.4. All reported regressions include country dummies. Inferences are, however, very similar when country dummies are omitted.

First, analyzing Panel A of Table 4.4, as indicated by significantly positive values on size, profitability, volatility and age, firms that load on these measures have higher future overnight returns. The coefficient estimate on book-to-market is negative, which implicates a negative return relation between the book-to-market ratio and future overnight returns. Nevertheless, controlling for the harder-to-value characteristics does not drive out the overnight return persistence in the cross-section of overnight returns. In fact, OVN remains an economically and statistically highly significant predictor for future overnight returns across all variables.

The signs on the interaction terms are consistent with our above-mentioned predictions. Every single interaction term between OVN and the hard-to-value dummy variable is significantly positive. These findings suggest that the positive overnight return persistence is stronger among firms that are objectively harder-to-value. In detail, for size, the average OVN coefficient estimate is 0.13 and the interaction term carries a value of 0.04 (t-statistic $=4.28$ ). Hence, the results imply that the OVN return persistence is larger and statistically significant among smaller firms with an estimate of 0.17 (formally, $0.13+0.04$ ). For bookto-market, the overnight coefficient estimate is 0.14 and the interaction term amounts to 0.02 $(\mathrm{t}$-statistic $=3.83)$. Therefore, the results conclude that firms with a higher book-to-market have a greater overnight return persistence. Firms with low profitability have a higher overnight return persistence manifested in a positive interaction term of 0.02 (t-statistic $=$ 6.71). The overnight returns persistence turns out to be stronger among more volatile firms with an estimate of 0.16 (formally, $0.14+0.02$ ). Finally, the results for age display that the

\footnotetext{
${ }^{18}$ The results remain very similar throughout week $\mathrm{w}+2$ to week $\mathrm{w}+4$.
} 
effect is stronger among younger firms, with an estimate of the interaction term of 0.06 (tstatistic $=9.09$ ).

Panel B of Table 4.4 includes common controls as further robustness checks of the stronger overnight return persistence among harder-to-value firms in the cross-sectional regression, namely beta, size, book-to-market, profitability, investment, and momentum as well as the particular harder-to-value characteristic if not already included in the common controls (VOL \& AGE). The interactions and dummy variables operate in the same way as in Panel A of Table 4.4. The results obtained correspond qualitatively to those presented in Panel A and thus lead to the same inferences. Even with several control variables the results for each of the harder-to-value characteristics remain economically and statistically significant; thus the overnight return persistence is stronger among firms that are harder to value.

In summary, the results in this section strongly support Hypothesis 2. Similar to the results of prior U.S. studies, the short-term overnight return persistence is stronger among firms that are harder to value, which provides further evidence that overnight returns are suitable as a firm-specific investor sentiment measure.

\subsection{Long-Term Reversal}

In this section, we test Hypothesis 3, that in the long-run stocks with high overnight returns significantly underperform those with low overnight returns. In other words, we shed light on the long-term return behavior of stocks with high and low overnight returns during the formation period. This reflects the third requirement for the usability of overnight returns as a measure of firm-specific sentiment. Aboody et al. (2018) document for the U.S. equity market that for the first year after portfolio formation based on the monthly overnight returns of December, the close-to-close return is significantly lower in the top decile than in the bottom decile. Therefore, we test in the following whether these findings also occur in our non-U.S. sample. 
We estimate monthly cross-sectional regressions of overlapping yearly close-to-close returns without control variables (Panel A of Table 4.5) and with the full set of the previously employed control variables that are either updated at the end of each June (BETA, SZ, BM, OP, INV) or monthly (MOM). The additional high (low) indicator is equal to one if the firm's overnight return of the past month is in the top (bottom) 20 per cent and zero otherwise. Our observation period starts in July 1992 and ends in June 2017.

Panel A of Table 4.5 presents average coefficient estimates from the outlined monthly firmlevel cross-sectional regression of overlapping yearly returns without controls to assess the long-run close-to-close return behavior. The last row provides the economic and statistical significance of the average return premium by reporting the difference between the high and low coefficient estimates. We find a significant negative premium of -0.76 for the first year, which is driven by a negative high indicator $(-0.50 \%)$ and a positive low indicator $(0.26 \%)$. The high-low premium stays significantly negative up to three years after portfolio formation and becomes insignificant thereafter.

Table 4.5 Cross-Sectional Regressions for Longer Holding Period Close-to-Close Returns

Panel A: Cross-Sectional Regressions of Close-to-Close Returns without Controls

\begin{tabular}{lccc}
\hline & Year 1 & Year 2 & Year 3 \\
\hline \multirow{2}{*}{ High } & -0.50 & -0.09 & -0.39 \\
\multirow{2}{*}{ Low } & $(-0.70)$ & $(-0.13)$ & $(-0.75)$ \\
& 0.26 & 1.78 & 1.34 \\
$\mathrm{R}^{2}$ & $(0.33)$ & $(2.30)$ & $(2.11)$ \\
High-Low & 0.09 & 0.09 & 0.09 \\
& & & -1.73 \\
& -0.76 & -1.87 & $(-3.53)$ \\
\hline
\end{tabular}


Chapter 4 Overnight Returns: An International Sentiment Measure

Panel B: Cross-Sectional Regressions of Close-to-Close Returns with Controls

\begin{tabular}{lccc}
\hline & Year 1 & Year 2 & Year 3 \\
\hline \multirow{2}{*}{ High } & -0.98 & -0.13 & -0.25 \\
& $(-2.31)$ & $(-0.29)$ & $(-0.71)$ \\
Low & -0.47 & 1.08 & 1.02 \\
BETA & $(-0.90)$ & $(1.80)$ & $(1.89)$ \\
& -0.48 & -0.55 & 0.56 \\
SZ & $(-0.71)$ & $(-0.87)$ & $(0.65)$ \\
& -0.66 & -0.18 & -0.08 \\
BM & $(-2.36)$ & $(-0.74)$ & $(-0.36)$ \\
& 3.12 & 1.96 & 1.59 \\
OP & $(4.48)$ & $(3.59)$ & $(3.39)$ \\
& 1.58 & 1.28 & 1.24 \\
INV & $(7.42)$ & $(5.77)$ & $(5.35)$ \\
& -2.11 & -1.40 & -1.27 \\
MOM & $(-2.34)$ & $(-1.85)$ & $(-1.48)$ \\
& 4.16 & -4.37 & -1.27 \\
$\mathrm{R}^{2}$ & $(1.59)$ & $(-3.10)$ & $(-1.00)$ \\
& & & 0.10 \\
High-Low & 0.11 & 0.10 & -1.27 \\
& & & -2.34 \\
\hline
\end{tabular}

This table presents average coefficient estimates and associated Newey-West adjusted $t$-statistics (in parentheses) from monthly firm-level cross-sectional regressions. The dependent variable is the firm's first-year, second-year or third-year return after the portfolio formation. High (low) indicator is equal to one if a firm's past monthly overnight return is in the top (bottom) 20 per cent and zero otherwise. See Table 4.3 for a description of the independent variables. In the regressions, SZ and $\mathrm{BM}$ are measured in natural logs. $\mathrm{R}^{2}$ is adjusted for degrees of freedom. The last row provides the average return premium. Panel A reports results for the high and low indicators without controls and Panel B reports results for the full set of independent controls (see Table 4.3).

Panel B of Table 4.5 includes the common controls as further robustness tests. The premium is insignificant for year one but significantly negative for years two and three after formation. Interestingly, the return on the high indicator is significantly negative for year one and diminishes in the following years. 
Table 4.5 provides insights into the long-run of close-to-close returns sorted on past overnight returns. In sum, the results support our Hypothesis 3 that stocks with high overnight returns yield significantly smaller risk-adjusted returns in the long-run. These results indicate a potential overpricing of firms with high overnight returns in the short-run compared to those with low overnight returns. Thus, our international results strongly confirm the findings of Aboody et al. (2018) and previous literature by Hvidkjaer (2008) or Barber et al. (2009a) in favor of temporary mispricing.

\subsection{Application Test}

In this section, we use the firm-specific investor sentiment measure to examine the explanatory power in the context of the momentum anomaly motivated by recent empirical evidence. Using the well-known sentiment index of Baker and Wurgler (2006), Antoniou et al. (2013) show that momentum is strongly affected by market-wide sentiment. ${ }^{19}$ This provides an ideal test-setting to not just examine whether overnight returns affect momentum in a similar way, but also to test the firm-specific sentiment character of overnight returns by analyzing the explanatory power beyond market-wide sentiment. Following Antoniou et al. (2013), we define momentum as the cumulative returns from month $\mathrm{t}-7$ to $\mathrm{t}-2$ and present results for holding periods of six months and 12 months as well as the period from month 13 to 24 after formation.

To study the relation between momentum and overnight returns, we employ a momentum control variable (MOM) and a dummy variable (HOVN) that is one if a firm's overnight return is in the top quintile during the formation month, and zero otherwise. As prior studies have shown, we expect a positive momentum effect for up to twelve months within our international sample, that turns negative in year two (Jegadeesh and Titman, 1993). If the overnight returns are suitable as a firm-specific sentiment measure we expect a significantly negative interaction term between momentum and the high overnight return dummy. In order

\footnotetext{
${ }^{19}$ Stambaugh et al. (2012) also provide similar results.
} 


\section{Chapter 4 Overnight Returns: An International Sentiment Measure}

to examine whether overnight returns have explanatory power beyond market-wide sentiment, we split our sample into two subsamples relating to the BW sentiment measure following Stambaugh et al. (2012). ${ }^{20}$ They suggest a high-sentiment month is one when the value of the measure in the previous month is about the median and zero otherwise. Thus, we have a subsample of high sentiment including 140 months of the observations period and a second subsample including 140 months of low sentiment. ${ }^{21}$

Table 4.6 presents average coefficient estimates from the outlined monthly cross-sectional regressions for our momentum measure. In Panel A of Table 4.6 we provide results that control only for momentum and for the full set of common controls in Panel B.

Analyzing the full Period of Panel A in Table 4.6, we find a significant momentum for a sixmonth $(4.79 \%)$ holding period as well as for a twelve-month $(5.43 \%)$ holding period that turns negative in year $2(-4.84 \%)$. For six- and for twelve-months our interaction (MOMxHOVN) is significantly negative $(-2.08 \%$ for six-months and $-3.17 \%$ for twelvemonths), these results show that our firm-specific international sentiment measure has explanatory power for the momentum anomaly. Specifically, stocks with a high past overnight return have a significantly negative impact on the momentum premium.

Table 4.6 Cross-Sectional Regressions of Momentum Conditional on Sentiment

Panel A: Cross-Sectional Regressions of Momentum without Controls

\begin{tabular}{lcccccccccc}
\hline & \multicolumn{4}{c}{ Full } & \multicolumn{4}{c}{ Low BW Sentiment } & \multicolumn{3}{c}{ High BW Sentiment } \\
& 6 Mo & Year 1 & Year 2 & 6 Mo & Year 1 & Year 2 & 6 Mo & Year 1 & Year 2 \\
\hline \multirow{3}{*}{ Momentum } & & & & & & & & & & \\
& 4.79 & 5.43 & -4.84 & 2.37 & -0.31 & -2.80 & 7.29 & 11.62 & -6.79 \\
MOMxHOVN & $(2.66)$ & $(2.02)$ & $(-2.80)$ & $(0.75)$ & $(-0.07)$ & $(-1.86)$ & $(4.53)$ & $(5.06)$ & $(-2.41)$ \\
& -2.06 & -3.17 & 0.51 & -2.59 & -2.90 & -0.87 & -1.69 & -3.55 & 1.83 \\
& $(-3.18)$ & $(-3.58)$ & $(0.54)$ & $(-3.14)$ & $(-3.05)$ & $(-1.01)$ & $(-1.87)$ & $(-2.40)$ & $(1.25)$ \\
$\mathrm{R}^{2}$ & & & & & & & & & \\
\hline
\end{tabular}

\footnotetext{
${ }^{20}$ The sentiment index is on Wurgler's website: http://pages.stern.nyu.edu/ jwurgler /.

${ }^{21}$ Given that data for Wurgler's sentiment is only available until 09/2015 the observation period in this section ends in the same month.
} 
Chapter 4 Overnight Returns: An International Sentiment Measure

Panel B: Cross-Sectional Regressions of Momentum with Controls

\begin{tabular}{lccccccccc}
\hline & \multicolumn{3}{c}{ Full } & \multicolumn{9}{c}{ Low BW Sentiment } & \multicolumn{3}{c}{ High BW Sentiment } \\
& 6 Mo & Year 1 & Year 2 & 6 Mo & Year 1 & Year 2 & 6 Mo & Year 1 & Year 2 \\
\hline \multirow{3}{*}{ Momentum } & & & & & & & & & \\
\multirow{3}{*}{ MOMxHOVN } & 4.07 & 5.31 & -4.85 & 2.17 & 0.38 & -3.73 & 5.90 & 10.61 & -5.91 \\
& $(2.35)$ & $(2.04)$ & $(-3.26)$ & $(0.69)$ & $(0.09)$ & $(-2.33)$ & $(4.26)$ & $(5.14)$ & $(-2.58)$ \\
BETA & -2.17 & -3.57 & 0.91 & -2.66 & -3.89 & -0.52 & -1.67 & -3.09 & 2.27 \\
& $(-3.83)$ & $(-4.55)$ & $(0.98)$ & $(-3.37)$ & $(-3.83)$ & $(-0.60)$ & $(-2.06)$ & $(-2.47)$ & $(1.59)$ \\
SZ & -0.26 & -0.65 & -0.57 & 0.09 & -0.06 & -1.30 & -0.86 & -1.60 & 0.14 \\
& $(-0.55)$ & $(-0.95)$ & $(-0.88)$ & $(0.12)$ & $(-0.05)$ & $(-2.15)$ & $(-1.73)$ & $(-2.68)$ & $(0.14)$ \\
BM & -0.28 & -0.65 & -0.20 & -0.54 & -1.24 & -0.09 & 0.09 & 0.01 & -0.31 \\
& $(-1.60)$ & $(-2.27)$ & $(-0.79)$ & $(-2.38)$ & $(-3.36)$ & $(-0.32)$ & $(0.38)$ & $(0.04)$ & $(-0.84)$ \\
OP & 1.75 & 3.10 & 1.98 & 0.60 & 1.13 & 2.46 & 3.01 & 5.07 & 1.49 \\
& $(4.53)$ & $(4.46)$ & $(3.66)$ & $(1.50)$ & $(1.54)$ & $(4.23)$ & $(5.52)$ & $(5.35)$ & $(2.08)$ \\
INV & 0.76 & 1.57 & 1.28 & 0.75 & 1.61 & 1.33 & 0.80 & 1.51 & 1.22 \\
& $(6.54)$ & $(7.47)$ & $(5.73)$ & $(4.08)$ & $(5.17)$ & $(5.05)$ & $(6.57)$ & $(6.83)$ & $(4.18)$ \\
& -1.65 & -2.17 & -1.37 & -0.59 & -0.73 & -2.63 & -2.59 & -3.24 & -0.15 \\
& $(-3.70)$ & $(-2.37)$ & $(-1.83)$ & $(-0.92)$ & $(-0.54)$ & $(-4.89)$ & $(-5.11)$ & $(-3.35)$ & $(-0.12)$ \\
$\mathrm{R}^{2}$ & & & & & & & & & \\
& 0.12 & 0.11 & 0.10 & 0.08 & 0.06 & 0.06 & 0.16 & 0.16 & 0.13 \\
\hline
\end{tabular}

This table presents average coefficient estimates and associated Newey-West adjusted $t$-statistics (in parentheses) from monthly firm-level cross-sectional regressions. The dependent variable is the firm's six-month, first-year or second-year return after the portfolio formation. Momentum is the cumulative prior six-month stock return, skipping the most recent month. HOVN is a dummy variable based on the monthly overnight return in the formation month. HOVN is equal to one if a firm's overnight return is in the top $20 \%$ for a given month and zero otherwise. The full sample covers the whole observation period (see Table 4.1). Low (high) BW sentiment samples cover all month with a Baker and Wurgler sentiment value in the previous month below (above) the median of all months between July 1992 and September 2015. In the regressions, SZ and BM are measured in natural logs. $\mathrm{R}^{2}$ is adjusted for degrees of freedom. Panel A reports results for momentum and the interaction term (MOMxHOVN). Panel B contains additional results for the full set of independent controls (see Table 4.3).

To test whether the firm-specific sentiment measure has explanatory power above and beyond the already known sentiment measures we take a closer look at the two subsamples here. First, analyzing the periods with low BW sentiment, we find that there is no momentum for the observed periods but our firm-specific measure is still significantly negative within 
the 6- and 12-months periods. ${ }^{22}$ Thus, even in cycles of low BW sentiment, we find that our measure has predictive power and yields significantly negative future returns for overpriced stocks. Second, periods of high BW sentiment display strong and highly significant momentum returns within the international sample but even in this subsample we have a negative interaction term of $-1.69 \%$ for the first six months that leads towards significance (t-statistic of -1.87) and a significantly negative value for the 12 -month period of $-3.55 \%$ ( $t$ statistic of -2.40). These results demonstrate that even in a positive market-wide BW sentiment, a firm-specific sentiment can determine mispriced stocks.

For the sake of completeness, we also provide results with the full set of common controls in Panel B of Table 4.6. The results are briefly summarized and strongly correspond with the results of Panel A. Our international firm-specific sentiment measure has predictive power for six-month and 12 month holding periods among the full observation period as well as the two subsamples.

Taken together, the results in this section strongly support the suitability of overnight returns as a sentiment measure and demonstrate the practical applicability of a firm-specific investor sentiment measure.

\subsection{Conclusion}

In this paper, we study the suitability of overnight returns as a firm-specific sentiment measure in equity markets outside the United States. We provide strongly supportive out-ofsample evidence on the previous U.S. findings by Aboody et al. (2018) using a broad sample of international equity markets during the time period 1992-2017.

To verify the suitability of overnight returns as a firm-specific sentiment measure three requirements have to be fulfilled. First, we find pervasive evidence of significant persistence in overnight returns in the short-run even after controlling for a large set of established return

\footnotetext{
${ }^{22}$ In line with prior U.S. findings of Antoniou et al. (2013), they find that momentum arises only in positive sentiment periods.
} 
predictors, such as beta, firm size, book-to-market, profitability, investment, and momentum. Second, studying the observed overnight return persistence in combination with harder-tovalue characteristics, we find that the persistence is stronger among firms that are objectively harder to value. Specifically, we follow Aboody et al. (2018) and categorize stocks that are small, have a high book-to-market ratio (as a measure of growth), a low profitability, a high past return volatility, or are young as harder-to-value. The third condition is that stocks with high overnight returns show a long-term reversal in close-to-close returns. For a period of up to three years, stocks with high short-term overnight returns yield significantly negative returns in comparison to stocks with low overnight returns, this corroborates a mispricingbased explanation.

Implementing overnight returns as a firm-specific sentiment measure within the momentum anomaly, we provide evidence that our sentiment measure possesses predictive power above and beyond the well-known market-wide sentiment index by Baker and Wurgler (2006). As a result, this study delivers a practicable method to measure firm-specific investor sentiment even outside the United States. 


\section{Chapter 5}

\section{Conclusion}

Momentum and sentiment measures are topics of broad interest and the debate about return behavior is ongoing. However, international literature on these topics is still scarce. This thesis contributes to the existing literature by examining novel momentum, as well as sentiment approaches in the broad set of international stock markets. For this purpose, the most recent trends and methods in asset pricing are considered and taken into account.

As a whole, the following research questions are considered in this thesis: Can momentum be separated from reversal in international stock markets? Is continuing overreaction a better predictor for future returns than past returns? Are overnight returns suitable as a measure of international firm specific investor sentiment? Hereafter, each of the three studies that contribute to the research questions is summarized briefly.

In the first study, "Separating Momentum from Reversal in International Stock Markets", a large international sample of 20 non-U.S. equity markets in a period from 1992 to 2017 is analyzed. Significantly larger momentum profits can be generated within a strategy that buys small value winners and sells large growth losers, the MAX strategy. Interestingly, the strategy does not suffer from return reversals, even for holding periods up to three years, and is robust to common return controls. In contrast, the MIN strategy that buys large growth winners and sells small value losers, produces no significant momentum profits, but significant return reversals over holding periods beyond one year. The significantly different return behavior of the MIN and MAX strategy is attributable to mispricing among momentum stocks. The superior performance of the MAX strategy is driven by undervalued winners and overvalued losers, while overvalued winners and undervalued losers drive the inferior performance of the MIN strategy. 


\section{Chapter 5 Conclusion}

The second study, "Continuing Overreaction: European Evidence”, investigates the U.S. findings of Byun et al. (2016) that a continuing overreaction measure can predict future stock returns in the broad cross-section of European firms drawn from 15 developed equity markets over the sample period from 1992 to 2017 . A significantly positive relation between firms continuing overreaction measure and the subsequent stock return is documented. The outperformance of companies with high $\mathrm{CO}$ over companies with low $\mathrm{CO}$ is not captured by established cross-sectional return determinants e.g., firm size, book-to-market and momentum as well as novel controls like profitability and investment. In addition, the premium is also present within different business conditions, as market volatility, market states, investor sentiment, market liquidity, default spread, and the NBER recession indicator. In depth, the novel $\mathrm{CO}$ measure earns a significantly positive return premium over a holding period of one year that does not suffer from reversal as a standard momentum approach does in the subsequent years.

Investigating a large international sample of 20 non-U.S. equity markets in a period from 1992 to 2017, the third study, "Overnight Returns: An International Sentiment Measure", finds strong evidence that overnight returns are suitable as a firm-specific sentiment measure. Overnight returns fulfill three characteristics that would be expected of a sentiment measure. First, overnight returns persist in the short run. Second, this persistence is stronger among harder-to-value firms. And third, stocks with high overnight returns underperform in the long run. The short-term persistence is not subsumed by established cross-sectional return determinants and is even pervasive across time and different regions. Equally, the stronger persistence among harder-to-value firms is still economically and statistically significant with the full set of control variables. Finally, when implementing overnight returns as a firm-specific sentiment measure, for instance within the momentum anomaly, there is explanatory power even beyond the market-wide sentiment measure by Baker and Wurgler (2006). 
Given the magnitude of momentum and reversal research and its continuing risk vs. mispricing debate, this dissertation gives valuable new insights. It also tackles substantial research topics regarding the popularity of investor sentiment and its role in explaining behavior-motivated asset pricing anomalies. Several implications can be derived for investors as well as for empirical finance literature.

Investors that focus on momentum strategies as one of the most examined return anomalies in empirical finance benefit when they separate momentum stocks from stocks that gain reversal. Due to the simple facts that a reallocation within a standard momentum approach is costly and the exact timing of the reallocation is hard, investors benefit from the novel approach. Given that the strategy gains significant abnormal returns over a holding period up to three years, investors can hold their stocks for the given period and save reallocation costs. The finding that the different return behavior of the two strategies is the result of a rather systematic exploitation of existing mispricing among momentum, plays an important role and sheds further light on the debate between risk-based or mispricing-based explanations and provides promising approaches for prospective research.

Further practical implication benefits are provided by the continuing overreaction measure and its superiority over the standard momentum approach. The advantages for investors are obvious due to a higher return premium and scarcer portfolio reallocation.

On the other hand, the suitability of overnight returns as a firm-specific investor sentiment measure, is important to both, researchers and investors. Overnight returns provide a more direct measure at the firm-level than a market-wide sentiment measure. This measure does not require any special datatype, which for instance is only available for the U.S. market. Therefore, the suitability of overnight returns as a measure of firm-specific sentiment offers the possibility of a comprehensive sentiment measure on international stock markets without data adoptions that can be implemented by institutional as well as retail investors. Against the background that literature on overnight returns is quite young and international evidence is scarce, further research is welcome. 


\section{Bibliography}

Aboody, D., Even-Tov, O., Lehavy, R. and Trueman, B. (2018) Overnight Returns and FirmSpecific Investor Sentiment. Journal of Financial and Quantitative Analysis 53(2): 485-505.

Ang, A., Hodrick, R.J., Xing, Y. and Zhang, X. (2009) High idiosyncratic volatility and low returns: International and further U.S. evidence. Journal of Financial Economics 91(1): 1-23.

Antoniou, C., Doukas, J.A. and Subrahmanyam, A. (2013) Cognitive Dissonance, Sentiment, and Momentum. Journal of Financial and Quantitative Analysis 48(1): 245-275.

Arif, S. and Lee, C. (2014) Aggregate Investment and Investor Sentiment. Review of Financial Studies 27(11): 3241-3279.

Asness, C. (2011) Momentum in Japan: The exception that proves the rule. Journal of Portfolio Management 37(4): 67-75.

Asness, C., Moskowitz, T.J. and Pedersen, L. H. (2013) Value and momentum everywhere. Journal of Finance 68(3): 929-985.

Baker, M. and Wurgler, J. (2006) Investor sentiment and the cross-section of stock returns. Journal of Finance 61(4): 1645-1680.

Baker, M., Wurgler, J. and Yuan, Y. (2012) Global, local, and contagious investor sentiment. Journal of Financial Economics 104(2): 272-287.

Barber, B. and Odean, T. (2001) Boys Will Be Boys: Gender, Overconfidence, and Common Stock Investment. Quarterly Journal of Economics 116(1): 261-292. 
Barber, B. and Odean, T. (2008) All That Glitters: The Effect of Attention and News on the Buying Behavior of Individual and Institutional Investors. Review of Financial Studies 21(2): 785-818.

Barber, B., Odean, T. and Zhu, N. (2009a) Do Retail Trades Move Markets? Review of Financial Studies 22(1): 151-186.

Barber, B., Odean, T. and Zhu, N. (2009b) Systematic Noise. Journal of Financial Markets 12(4): 547-569.

Barberis, N. and Thaler, R. (2003) A survey of behavioral finance. Chapter 18 in Handbook of the Economics of Finance 1(2): 1053-1128.

Barberis, N., Shleifer, A. and Vishny R. (1998) A model of investor sentiment. Journal of Financial Economics 49(3): 307-343.

Barberis, N., Shleifer, A. and Wurgler, J. (2005) Comovement. Journal of Financial Economics 75(2): 283-317.

Basu, S. (1977) Investment Performance of Common Stocks in Relation to Their PriceEarnings Ratios: A Test of the Efficient Market Hypothesis. Journal of Finance 32(3): 663-682.

Benos, A.V. (1998) Aggressiveness and Survival of Overconfident Traders. Journal of Financial Markets 1(3-4): 353-383.

Berkman, H., Dimitrov, V., Jain, P., Koch, P. and Tice, S. (2009) Sell on the news: Differences of opinion, short-sales constraints, and returns around earnings announcements. Journal of Financial Economics 92(3): 376-399.

Berkman, H., Koch, P., Tuttle, L. and Zhang, Y. (2012) Paying Attention: Overnight Returns and the Hidden Cost of Buying at the Open. Journal of Financial and Quantitative Analysis 47(4): 715-741. 


\section{Bibliography}

Blackburn, D.W. and Cakici, N. (2017) Overreaction and the cross-section of returns: International evidence. Journal of Empirical Finance 42: 1-14.

Bradshaw, M.T., Richardson, S.A. and Sloan, R.G. (2006) The relation between corporate financing activities, analysts forecasts and stock returns. Journal of Accounting and Economics 42(1-2): 53-85.

Branch, B. and Ma, A. (2008) The Overnight Return, One More Anomaly. University of Massachusetts, Working Paper.

Brown, G. and Cliff, M. (2004) Investor sentiment and the near-term stock market. Journal of Empirical Finance 11(1): 1-27.

Byun, S.J., Lim, S.S. and Yun, S. H. (2016) Continuing overreaction and stock return predictability. Journal of Financial and Quantitative Analysis 51(6): 2015-2046.

Carhart, M.M. (1997) On Persistence in Mutual Fund Performance. Journal of Finance 52(1): 57-82.

Chen, H. and DeBondt, W. (2004) Style momentum within the S\&P-500 index. Journal of Empirical Finance 11(4): 483-507.

Chordia, T. and Shivakumar, L. (2002) Momentum, Business Cycle, and Time-varying Expected Returns. Journal of Finance 57(2): 985-1019.

Chui, A.C.W., Titman, S. and Wei, K.C.J. (2010) Individualism and momentum around the world. Journal of Finance 65(1): 361-392.

Conrad, J. and Kaul, G. (1998) An anatomy of trading strategies. Review of Financial Studies 11(3): 489-519.

Conrad, J. and Yavuz, M.D. (2017) Momentum and reversal: Does what goes up always come down? Review of Finance 21(2): 555-581. 
Cooper, M.J., Gutierrez Jr., R.C. and Hameed, A. (2004) Market states and momentum. Journal of Finance 59(3): 1345-1365.

Daniel, K., Hirshleifer, D. and Subrahmanyam, A. (1998) Investor psychology and security market under- and overreactions. Journal of Finance 53(6): 1839-1885.

De Bondt, W.F.M. and Thaler, R. (1985) Does the Stock Market Overreact? Journal of Finance 40(3): 793-805.

De Bondt, W.F.M. and Thaler, R. (1987) Further Evidence on Investor Overreaction and Stock Market Seasonality. Journal of Finance 42(3): 557-81.

De Long, J.B., Shleifer, A., Summers, L.H. and Waldmann, R.J. (1990) Noise trader risk in financial markets. Journal of Political Economy 98(4): 703-738.

De Long, J.B., Shleifer, A., Summers, L.H. and Waldmann, R.J. (1991) The survival of noise trader risk in financial markets. The Journal of Business 64(1): 1-19.

Eun, C. and Lee, J. (2010) Mean-variance convergence around the world. Journal of Banking \& Finance 34(4): 856-870.

Fama, E.F. (1991) Efficient Capital Markets: II. Journal of Finance 46(5): 1575-1617.

Fama, E.F. (1998) Market efficiency, long-term returns, and behavioral finance. Journal of Financial Economics 49(3): 283-306.

Fama, E.F. and French, K.R. (1992) The cross-section of expected stock returns. Journal of Finance 47(2): 427-465.

Fama, E.F. and French, K.R. (1993) Common risk factors in the returns on stocks and bonds. Journal of Financial Economics 33(1): 3-56. 


\section{Bibliography}

Fama, E.F. and French, K.R. (1996) Multifactor Explanations of Asset Pricing Anomalies. Journal of Finance 51(1): 55-84.

Fama, E.F. and French, K.R. (2012) Size, value, and momentum in international stock returns. Journal of Financial Economics 105(3): 457-472.

Fama, E.F. and French, K.R. (2015) A five-factor asset pricing model. Journal of Financial Economics 116(1): 1-22.

Fama, E.F. and French, K.R. (2017) International tests of a five-factor asset pricing model. Journal of Financial Economics 123(3): 441-463.

Fama, E.F. and MacBeth, J.D. (1973) Risk, return, and equilibrium: Empirical tests. Journal of Political Economy 81(3): 607-636.

Feng, L. and Seasholes, M.S. (2004) Correlated trading and location. Journal of Finance 59(5): 2117-2144.

Frazzini, A., Israel, R. and Moskowitz, T.J. (2018) Trading costs. AQR Capital and Yale School of Management, Working paper.

Gao, L. and Süss, S. (2015) Market Sentiment in Commodity Futures Returns. Journal of Empirical Finance 33(C): 84-103.

Gervais, S. and Odean, T. (2001) Learning to Be Overconfident. Review of Financial Studies 14(1): 1-27.

Glaser, M. and Weber, M. (2009) Which Past Returns Affect Trading Volume? Journal of Financial Markets 12(1): 1-31.

Grinblatt, M. and Keloharju, M. (2009) Sensation Seeking, Overconfidence, and Trading Activity. Journal of Finance 64(2): 549-578. 
Hirshleifer, D. and Jiang, D. (2010) A financing-based misvaluation factor and the crosssection of expected returns. Review of Financial Studies 23(9): 3401-3436.

Hong, H. and Stein, J.C. (1999) A Unified Theory of Underreaction, Momentum Trading, and Overreaction in Asset Markets. Journal of Finance 54(6): 2143-2184.

Hribar, P. and McInnis, J. (2012) Investor Sentiment and Analysts' Earnings Forecast Errors. Management Science 58(2): 293-307.

Hu, G.X., Pan, J. and Wang, J. (2013) Noise as information for illiquidity. Journal of Finance 68(6): 2341-2382.

Huang, D., Jiang, F., Tu, T. and Zhou, G. (2015) Investor Sentiment Aligned: A Powerful Predictor of Stock Returns. Review of Financial Studies 28(3): 791-837.

Hvidkjaer, S. (2008) Small Trades and the Cross-Section of Stock Returns. Review of Financial Studies 21(3): 1123-1151.

Ikenberry, D., Lakonishok, J. and Vermaelen, T. (1995) Market underreaction to open market share repurchases. Journal of Financial Economics 39(2-3): 181-208.

Jackson, A. (2003) The aggregate behavior of individual investors. London Business School, Working Paper.

Jegadeesh, N. (1990) Evidence of Predictable Behavior of Security Returns. Journal of Finance 45(3): 881-898

Jegadeesh, N. and Titman, S. (1993) Returns to buying winners and selling losers: Implications for stock-market efficiency. Journal of Finance 48(1): 65-91.

Jegadeesh, N. and Titman, S. (1995) Overreaction, Delayed Reaction, and Contrarian Profits. Review of Financial Studies 8(4): 973-93 


\section{Bibliography}

Jegadeesh, N. and Titman, S. (2001) Profitability of momentum strategies: An evaluation of alternative explanations. Journal of Finance 56(2): 699-720.

Jegadeesh, N. and Titman, S. (2002) Cross-sectional and time-series determinants of momentum returns. Review of Financial Studies 15(1): 143-157.

Jegadeesh, N. and Titman, S. (2011) Momentum. Annual Review of Financial Economics 3: 493-509.

Johnson, T.C. (2002) Rational Momentum Effects. Journal of Finance 57(2): 585-608.

Kaniel, R., Saar, G. and Titman, S. (2008) Individual investor trading and stock returns. Journal of Finance 63(1): 273-310.

Karolyi, G. A. (2016) Home bias, an academic puzzle. Review of Finance 20(1): 2049-2078.

Kumar, A. and Lee, C.M.C. (2006) Retail investor sentiment and return comovements. Journal of Finance 61(5): 2451-2486.

Lakonishok, J., Shleifer, A. and Vishny, R. (1994) Contrarian Investment, Extrapolation, and Risk. Journal of Finance 49(5): 1541-1578.

Lee, C.M.C., Shleifer, A. and Thaler, R.H. (1991) Investor Sentiment and the Closed-End Fund Puzzle. Journal of Finance 46(1): 75-109.

Lehmann, B. (1990) Fads, Martingales, and Market Efficiency. Quarterly Journal of Economics 105(1): 1-28.

Lintner, J. (1965) The Valuation of Risk Assets and the Selection of Risky Investments in Stock Portfolios and Capital Budgets. The Review of Economics and Statistics 47(1): 13-37. 
Lo, A.W. and MacKinlay, A.C. (1990) Data-snooping biases in tests of financial asset pricing models. Review of Financial Studies 3(3): 431-467.

Lou, D., Polk, C. and Skouras, S. (2019) A tug of war: Overnight versus intraday expected returns. Journal of Financial Economics 134(1): 192-213.

Loughran, T. and Ritter, J. (1995) The new issues puzzle. Journal of Finance 50(1): 23-51.

McLean, D.R. and Pontiff, J. (2016) Does Academic Research Destroy Stock Return Predictability? Journal of Finance 71(1): 5-32.

Mian, G. and Sankaraguruswamy, S. (2012) Investor Sentiment and Stock Market Response to Earnings News. The Accounting Review 87(4): 1357-1384.

Moskowitz, T.J. and Grinblatt, M. (1999) Do industries explain momentum? Journal of Finance 54(4): 1249-1290.

Newey, W.K. and West, K.D. (1987). A simple, positive semi-definite, heteroskedasticity and autocorrelation consistent covariance matrix. Econometrica 55(3): 703-708.

Novy-Marx, R. and Velikov, M. (2016). A taxonomy of anomalies and their trading costs. Review of Financial Studies 29(1): 104-147.

Odean, T. (1998) Volume, Volatility, Price, and Profit When All Traders Are Above Average. Journal of Finance 53(6): 1887-1934.

Rapach, D.E., Strauss, J.K. and Zhou, G. (2013) International stock return predictability: What is the role of the United States? Journal of Finance 68(4): 1633-1662.

Rouwenhorst, K.G. (1998) International momentum strategies. Journal of Finance 53(1): 267-284. 


\section{Bibliography}

Sagi, J.S. and Seasholes, M.S. (2007) Firm-specific attributes and the cross-section of momentum. Journal of Financial Economics 84(2): 389-434.

Schmeling, M. (2009) Investor sentiment and stock returns: Some international evidence. Journal of Empirical Finance 16(3): 394-408.

Seybert, N. and Yang, H. (2012) The Party's Over: The Role of Earnings Guidance in Resolving Sentiment-Driven Overvaluation. Management Science 58(2): 308-319.

Sharpe, W. F. (1964) Capital Asset Prices: A Theory of Market Equilibrium under Conditions of Risk. Journal of Finance 19(3): 425-442.

Shleifer, A. and Summers, L.H. (1990) The noise trader approach to finance. Journal of Economic Perspectives 4(2): 19-33.

Shleifer, A. and Vishny, R.W. (1997). The limits to arbitrage. Journal of Finance 52(1): 3555.

Stambaugh, R., Yu, J. and Yuan, Y. (2012) The Short of It: Investor Sentiment and Anomalies. Journal of Financial Economics 104(2): 288-302.

Statman, M., Thorley, S., and Vorkink, K. (2006) Investor Overconfidence and Trading Volume. Review of Financial Studies 19(4): 1531-1565.

Walkshäusl, C. (2016) Mispricing and the five-factor model. Economics Letters 147(C): 99102.

Walkshäusl, C. (2017) Expectation Errors in European Value-Growth Strategies. Review of Finance 21(2): 845-870. 